\title{
Optogenetic Central Amygdala Stimulation Intensifies and Narrows Motivation for Cocaine
}

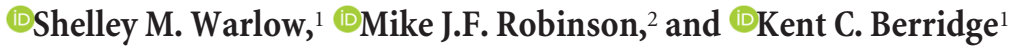 \\ ${ }^{1}$ Department of Psychology, University of Michigan, Ann Arbor, Michigan 48109, and ²Department of Psychology, Wesleyan University, Middletown, \\ Connecticut 06459
}

\begin{abstract}
Addiction is often characterized by intense motivation for a drug, which may be narrowly focused at the expense of other rewards. Here, we examined the role of amygdala-related circuitry in the amplification and narrowing of motivation focus for intravenous cocaine. We paired optogenetic channelrhodopsin (ChR2) stimulation in either central nucleus of amygdala (CeA) or basolateral amygdala (BLA) of female rats with one particular nose-poke porthole option for earning cocaine infusions $(0.3 \mathrm{mg} / \mathrm{kg}$, i.v.). A second alternative porthole earned identical cocaine but without ChR2 stimulation. Consequently, CeA rats quickly came to pursue their CeA ChR2-paired cocaine option intensely and exclusively, elevating cocaine intake while ignoring their alternative cocaine alone option. By comparison, BLA ChR2 pairing failed to enhance cocaine motivation. CeA rats also emitted consummatory bites toward their laser-paired porthole, suggesting that higher incentive salience made that cue more attractive. A separate progressive ratio test of incentive motivation confirmed that CeA ChR2 amplified rats' motivation, raising their breakpoint effort price for cocaine by 10 -fold. However, CeA ChR2 laser on its own lacked any reinforcement value: laser by itself was never self-stimulated, not even by the same rats in which it amplified motivation for cocaine. Conversely, CeA inhibition by muscimol/baclofen microinjections prevented acquisition of cocaine selfadministration and laser preference, whereas $\mathrm{CeA}$ inhibition by optogenetic halorhodopsin suppressed cocaine intake, indicating that CeA circuitry is needed for ordinary cocaine motivation. We conclude that CeA ChR2 excitation paired with a cocaine option specifically focuses and amplifies motivation to produce intense pursuit and consumption focused on that single target.
\end{abstract}

Key words: addiction; amygdala; intravenous self-administration; motivation; reward

\section{Significance Statement}

In addiction, intense incentive motivation often becomes narrowly focused on a particular drug of abuse. Here we show that pairing central nucleus of amygdala (CeA) optogenetic stimulation with one option for earning intravenous cocaine makes that option almost the exclusive focus of intense pursuit and consumption. CeA stimulation also elevated the effort cost rats were willing to pay for cocaine and made associated cues become intensely attractive. However, we also show that CeA laser had no reinforcing properties at all when given alone for the same rats. Therefore, CeA laser pairing makes its associated cocaine option and cues become powerfully attractive in a nearly addictive fashion.

\section{Introduction}

In addiction, intense motivation often becomes narrowly focused on an addictive reward target, whereas other alternative rewards

\footnotetext{
Received Oct. 10, 2016; revised June 3, 2017; accepted June 9, 2017.

Author contributions: S.M.W., M.J.F.R., and K.C.B. designed research; S.M.W. performed research; S.M.W., M.J.F.R., and K.C.B. analyzed data; S.M.W., M.J.F.R., and K.C.B. wrote the paper.

This work was supported by the National Institutes of Health (Grants DA015188 and MH63649 to K.C.B. and Grant T32 DC00011 to S.M.W.). We thank Cody Schember, Josh Goldman, and Nina Mostovoi for technical assistance and histology; Marc Bradshaw and Christopher Broussard for equipment construction; and Daniel Castro for figure assistance.

The authors declare no competing financial interests.

Correspondence should be addressed to Shelley Warlow, Department of Psychology, University of Michigan, 530 Church St., Ann Arbor, Ml 48109. E-mail: smwarlow@umich.edu.

DOI:10.1523/JNEUROSCI.3141-16.2017

Copyright $\odot 2017$ the authors $\quad 0270-6474 / 17 / 378330-19 \$ 15.00 / 0$
}

may be relatively ignored. How does limbic circuitry narrow the focus of incentive motivation to a single drug target, making that target more intensely 'wanted' at the expense of other alternatives?

Amygdala-related circuitry assigns motivational significance to particular stimuli based partly on associative information (Weiskrantz, 1956; LeDoux, 2000; Balleine and Killcross, 2006; Mahler and Berridge, 2009; Haubensak et al., 2010; DiFeliceantonio and Berridge, 2012; Peck et al., 2013; Janak and Tye, 2015; Yasoshima et al., 2015). In human addicts, drug cues can activate amygdala and related mesocorticolimbic circuitry and trigger urges to take drugs (Tang et al., 2012; Volkow et al., 2013). Within the amygdala, the basolateral nucleus (BLA) and the central nucleus (CeA) are serially connected. However, the CeA may be especially effective in generating intense incentive motivation that is narrowly focused 
on a particular stimulus target when neurochemically or optogenetically stimulated (Mahler and Berridge, 2009; DiFeliceantonio and Berridge, 2012; Robinson et al., 2014; Seo et al., 2016). The $\mathrm{CeA}$ is also implicated in the strengthening of cue-triggered craving for addictive drugs during incubation in animals ( $\mathrm{Lu}$ et al., 2005; Lu et al., 2007; Li et al., 2015), which might reflect incentive sensitization. The special role of CeA in generating intense motivation may be related to its status as a GABAergic "striatum-level structure" within a cortico-striato-pallidal macrosystem framework (Alheid and Heimer, 1988; Swanson and Petrovich, 1998; Zahm, 2006).

In a previous study, we reported that associative pairing of brief optogenetic ChR2 stimulations of CeA with pressing a particular lever to obtain sucrose pellet rewards caused rats to pursue that sole sucrose option intensely and narrowly, whereas ignoring an alternative lever that earned equal sucrose but without laser (Robinson et al., 2014). However, seemingly paradoxically, the CeA ChR2 stimulation by itself appeared worthless as a reinforcer to the same rats, as indicated by their failure to self-stimulate for CeA laser illumination by itself. This discrepancy suggested that value was not simply transferred from CeA ChR2 activation as an additive reinforcement signal, but rather that CeA ChR2 actively transformed the motivational value specifically of the laser-paired lever or its sucrose reward to make that reward option exclusively and intensely more attractive than the alternative (Robinson et al., 2014).

Our hypothesis is that stimulation of CeA circuitry narrows the focus of incentive motivation to its paired reward target and simultaneously raises the intensity of attraction, as happens in addiction. If so, then CeA ChR2 control of incentive motivation should also apply to earning an addictive drug reward such as intravenous cocaine. Here, we tested whether CeA ChR2 pairing would intensify and narrow pursuit to a single paired cocaine self-administration option while making rats ignore another alternative and equally good cocaine option. Our results confirmed that prediction and showed further that intense consummatory oral responses, including bites, became directed toward the paired metal cocaine-associated porthole as though unusually intense incentive salience were attributed to that paired cue. Further, CeA ChR2 stimulation also intensified the breakpoint effort price that rats were willing to pay for cocaine, which further indicates amplification of incentive motivation. Conversely, normal CeA function appeared to be needed for cocaine self-administration acquisition in this task because CeA pharmacological inhibition completely prevented self-administration acquisition in our two-choice task and halorhodopsin inhibition of CeA slightly suppressed cocaine intake. However, CeA ChR2 excitation alone completely failed to support any self-stimulation behavior, even in the same rats in which it controlled cocaine motivation. That is, rats refused to touch a spout to earn laser illumination and would not perform nose pokes or return to a place to self-stimulate CeA ChR2 photoexcitations. Therefore, CeA ChR2 stimulation intensified and narrowed motivation for its paired cocaine option to produce single-minded pursuit and consumption of the paired drug reward despite having no independent reinforcement value. These results suggest that CeA circuitry can enhance the attractiveness of a particular drug reward and associated stimuli and narrow the focus of incentive motivation specifically to that reward in a way that may be relevant to addiction.

\section{Materials and Methods Subjects}

Female Sprague Dawley rats $(n=55)$, weighing $250-300 \mathrm{~g}$ at surgery, were housed at $\sim 21^{\circ} \mathrm{C}$ constant temperature on a reverse $12 \mathrm{~h} \mathrm{light/dark}$ cycle. Estrus cycle was monitored via cervical smear. All rats had ad libitum access to both food and water in their home cage throughout the experiment. All experimental procedures were approved by the University Committee on the Use and Care of Animals at the University of Michigan.

\section{Surgery}

\section{Optogenetic virus infusion and optic fiber implant}

Rats were anesthetized with intraperitoneal injections of ketamine (100 mg/kg; Henry Schein) and xylazine (7 mg/kg; Henry Schein) and received atropine $(0.04 \mathrm{mg} / \mathrm{kg}$; Henry Schein) before surgery. At surgery, each rat also received subcutaneous injections of chloramphenicol sodium succinate $(60 \mathrm{mg} / \mathrm{kg}$, Henry Schein) to prevent infection and carprofen ( $5 \mathrm{mg} / \mathrm{kg}$, Henry Schein) for pain relief. Rats again received carprofen $(5 \mathrm{mg} / \mathrm{kg}) 24 \mathrm{~h}$ later and were allowed at least 3 weeks for recovery and viral expression before behavioral testing began. Each rat was placed in a stereotaxic apparatus (David Kopf Instruments) and received bilateral infusions of an AAV ChR2 virus with human Synapsin promoter to infect neurons (AAV5-Hsyn-ChR2-eYFP; UNC Vector Core, Chapel Hill, NC). Virus infusions were targeted either into the central nucleus of amygdala (CeA; bregma A/P: $-2.4, \mathrm{M} / \mathrm{L}: \pm 4.0, \mathrm{D} / \mathrm{V}:-7.6$; mouth bar set to $-3.3 ; n=15)$ or into the basolateral amygdala as an anatomical comparison site (BLA; A/P: $-1.92, \mathrm{M} / \mathrm{L}: \pm 5.0, \mathrm{D} / \mathrm{V}:-8.0$; mouth bar set to $-3.3 ; n=6)$. A total of $1 \mu$ l volume of virus per side was infused over $10 \mathrm{~min}$ at a constant rate $(0.1 \mu \mathrm{l} / \mathrm{min})$, and the injector was subsequently left in place for an additional $10 \mathrm{~min}$ to allow for diffusion. To test the effects of optogenetic inhibition in a separate group of rats $(n=7)$, a $1 \mu$ l volume of the inhibitory AAV halorhodopsin virus under the human synapsin promoter was infused into CeA using the same coordinates and at the same rate (AAV5-HSYN-eNpHR3.0-eYFP, UNC Vector Core). To serve as inactive virus controls, other rats received an infusion of optically inactive control virus that was identical except that it lacked either the ChR2 or the eNpHR3.0 gene ( $n=10$; AAV5-HsyneYFP, UNC Vector Core). For all rats receiving virus in CeA, bilateral fiber optics $(200 \mu \mathrm{m})$ were implanted during the same surgery, each aimed at $0.3 \mathrm{~mm}$ dorsal to the rat's virus infusion.

To test the effects of pharmacological inhibition of CeA and to assess normal function contribution to cocaine motivation via muscimol/baclofen microinjections, a separate group of rats $(n=9)$ were implanted with microinjection guide cannulae bilaterally with tips located $1 \mathrm{~mm}$ above CeA (22-gauge stainless steel, $11 \mathrm{~mm}$ long; Plastics One; $\mathrm{AP} \sim-2, \mathrm{ML} \sim 4, \mathrm{DV} \sim 6.8$ ). Dummy cannulas were inserted to prevent occlusion.

Finally, we tested the combination of optogenetic stimulation plus pharmacological inhibition at the same CeA site to assess whether muscimol/baclofen microinjections would prevent CeA ChR2 optogenetic stimulation from enhancing cocaine motivation. A separate group of rats initially received only bilateral CeA ChR2 virus (AAV5-Hsyn-ChR2-eYFP). During intrajugular catheter implantation 3 weeks later, these same animals were also implanted with bilateral chronic guide cannula with tips implanted $1 \mathrm{~mm}$ above the same CeA virus sites $(n=8)$.

\section{Intravenous catheter implantation}

Chronic intravenous jugular catheters for subsequent intravenous delivery of cocaine solutions were implanted in a separate surgery $\sim 3$ weeks later (Crombag et al., 2001). Briefly, after similar anesthesia and perioperative treatment as above, a Silastic intrajugular catheter (internal diameter $=0.28 \mathrm{~mm}$; external diameter $=0.61 \mathrm{~mm}$; dead volume $=12 \mu$; Plastics One) was threaded into the right jugular vein. The outer end was passed under the skin toward the head along the dorsal neck and exited from a secure subcutaneous anchor at the midscapular region. Rats were allowed to recover for 7-10 d after surgery before beginning behavioral training. Catheters were flushed daily with a $0.2 \mathrm{ml}$ of isotonic saline solution containing $5 \mathrm{mg} / \mathrm{ml}$ gentamicin sulfate (Sparhawk) to prevent infection and occlusions for the first $10 \mathrm{~d}$. After $10 \mathrm{~d}$, catheters continued to be flushed daily with $0.2 \mathrm{ml}$ of sterile isotonic saline alone (without gentamicin). Catheter patency was tested once before behavioral testing and again after the end of all tests by making an intravenous injection of $0.2 \mathrm{ml}$ of methohexital sodium to induce anesthesia $(20 \mathrm{mg} / \mathrm{ml}$ in sterile 
water; JHP). Rats that became ataxic within $10 \mathrm{~s}$ were considered to have a patent catheter and were included in behavioral analyses.

\section{Behavioral procedures}

Instrumental choice of laser + cocaine versus cocaine alone Excitation of amygdala. Briefly, each rat was trained to earn intravenous cocaine infusions instrumentally by making nose pokes into either one of two portholes and then choosing between them. The portholes were on the same wall $\sim 5 \mathrm{~cm}$ apart and detected nose pokes via beam breaks. Both portholes delivered cocaine infusions $(0.3 \mathrm{mg}$ salt weight per $\mathrm{kg}$ weight of the rat in $50 \mu \mathrm{l}$ volume infused over $2.8 \mathrm{~s}$; National Institute on Drug Abuse, Bethesda) dissolved in $0.9 \%$ sterile saline on a fixed ratio 1 (FR1) schedule. In addition, one porthole (laser + cocaine port) arbitrarily designated for each rat delivered an $8 \mathrm{~s}$ optogenetic CeA ChR2 or BLA ChR2 stimulation $(8-10 \mathrm{~mW}$ blue laser at $473 \mathrm{~nm}, 25 \mathrm{~Hz}, 15 \mathrm{~ms}$ ON, $25 \mathrm{~ms}$ OFF for $8 \mathrm{~s}$ train), which began with the final nose poke and continued during and immediately after the infusion. Stimulation parameters were based on Kravitz and Kreitzer (2011) and Robinson et al. (2014). The $8 \mathrm{~s}$ duration was aimed to paste photoexcitation onto the auditory cue at time of reward delivery. The other porthole (cocaine alone) delivered an equal infusion of cocaine alone, but without any laser illumination. Each port's infusion was also accompanied by a distinctive $8 \mathrm{~s}$ auditory cue (either white noise or tone counterbalanced between the two ports). Both portholes were permanently fixed in position for some rats $(n=9 \mathrm{CeA}$ ChR $2 ; n=2 \mathrm{BLA}$ ChR 2$)$ and always present in the chamber: each was illuminated whenever it was active and able to earn cocaine. Both portholes were movable for other rats ( $n=5$ CeA ChR2: 4 bilateral CeA illumination; 1 unilateral CeA illumination; $n=4$ BLA ChR2). Movable portholes were usually kept retracted into the wall and were only inserted into the chamber when actively available to earn cocaine. At the beginning of each session, for both porthole types, only one porthole was actively available to earn cocaine (illuminated if fixed in place; inserted into the chamber if movable). Next, only the alternative porthole was activated (illuminated or inserted), whereas the first porthole was dimmed or retracted. This initial one-at-a-time presentation ensured that a rat was exposed to each porthole and its outcome every day. Subsequently, both portholes were inserted or illuminated together for the remainder of each session, allowing the rat to choose freely between the two portholes for the rest of the hour. Chambers (Med Associates) with clear Plexiglas floors $(30.5 \times 24.1 \times 21.0 \mathrm{~cm})$ were used for training and testing instrumental cocaine self-administration and contained an auditory speaker (for tone/white noise components of conditioned stimulus, CS). An infusion pump was located outside of the sound-attenuated chamber to allow for cocaine delivery. A video camera placed below the transparent chamber floor recorded the rat's behavior for subsequent analysis of consummatory behaviors and stereotypy.

Rats were trained and tested for $10 \mathrm{~d}$ on instrumental self-administration of intravenous cocaine (CeA ChR2 virus: $n=15$; BLA ChR2 virus: $n=6$; CeA/BLA control inactive virus: $n=8$; CeA eNpHR (halorhodopsin) inhibitory opsin virus: $n=7$ ). The first day began with a $2 \mathrm{~h}$ session and subsequent days were $1 \mathrm{~h}$ sessions. Nose pokes into either porthole earned a $0.3 \mathrm{mg} / \mathrm{kg}$ infusion of cocaine hydrochloride. The session always began with one porthole illuminated or inserted and available to earn cocaine (either laser + cocaine or cocaine alone, with the order counterbalanced across rats). Once cocaine was earned, the other porthole was activated next until cocaine was earned on it. This one-at-a-time presentation cycle was repeated a second time. Subsequently, both portholes remained equally available to earn cocaine for the rest of the session. Assignment of an auditory cue to laser-paired porthole versus the different auditory cue to the cocaine-alone porthole was always the same for a given rat across all days, but was counterbalanced between rats. For both portholes, a $20 \mathrm{~s}$ timeout period was imposed after each cocaine infusion earned, during which subsequent nose pokes into either hole had no consequence (see Fig. 1). Rats were required to sample from both cocaine-delivering ports at least twice each day on the first $2 \mathrm{~d}$ and all rats met this criterion and so continued in the experiment: $85 \%$ of rats (11/ 13) within the first hour on the first day, the remaining $15 \%$ during the second hour of the first day, and $100 \%$ in the first hour on the second day. All subsequent sessions lasted $60 \mathrm{~min}$ or 40 infusions, whichever oc- curred first. Any rat that failed to nose poke at least 5 times per session over three consecutive sessions within the first $10 \mathrm{~d}$ was excluded from analyses $(n=2)$. For all rats, every nose poke earned a cocaine infusion on an FR1 schedule throughout days 1-10 (i.e., one nose poke earned an infusion, followed by $20 \mathrm{~s}$ timeout).

Inhibition of amygdala (halorhodopsin or muscimol/baclofen). For rats receiving halorhodopsin inhibition of CeA for loss-of-function studies $(n=7)$, all procedures were identical except that a constant yellow laser $(8-10 \mathrm{~mW}, 592 \mathrm{~nm})$ was bilaterally substituted for CeA illumination in place of blue laser during training. The yellow laser $(592 \mathrm{~nm} ; 8 \mathrm{~s}$ constant duration; $8-10 \mathrm{~mW}$ ) was associatively paired with each time cocaine was earned on one of the two cocaine portholes. CeA halorhodopsin rats were trained either with fixed nose-poke ports ( $n=2$ rats) or retractable ports that were usually retracted but phasically inserted separately for initial one-at-a time self-administration opportunities each session or together to allow choice between the two for the remainder of each session $(n=5$ rats). Training at an FR1 schedule continued for $10 \mathrm{~d}$ as above, with $8 \mathrm{~s}$ yellow laser bins paired with one cocaine option (counterbalanced across rats). On an additional day 11 test, the yellow laser was illuminated constantly for the entire $1 \mathrm{~h}$ session $(592 \mathrm{~nm}, 8-10 \mathrm{~mW})$, whereas rats received the same schedule of cocaine options as on days 1-10 to detect whether constant optogenetic CeA inhibition would suppress cocaine consumption.

For rats receiving pharmacological GABAergic inhibition of CeA daily during training (muscimol/baclofen: $n=5$ rats; vehicle: $n=4$ rats), bilateral microinjections were delivered $15 \mathrm{~min}$ before the rat was placed in the self-administration chamber beginning on day 3 and for each day following. To give microinjections, a rat was gently cradled by the experimenter's arms and microinjectors were inserted into each bilateral guide cannula (microinjectors $=21 \mathrm{~mm}$ long, so as to extend $1 \mathrm{~mm}$ below ventral tip of guide cannula; Plastics One). Bilateral microinjections of a mixture of $\mathrm{GABA}_{\mathrm{A}}$ agonist muscimol (Tocris Bioscience) and the $\mathrm{GABA}_{\mathrm{B}}$ agonist baclofen (Tocris Bioscience) $(0.1 \mu \mathrm{g} / 0.2 \mu \mathrm{l}$ of each combined in a single $0.5 \mu$ l volume of artificial CSF, ACSF) was delivered per side. Vehicle control rats received identical volume microinjections of ACSF alone. Doses and volumes were based on prior studies using muscimol/baclofen combinations in amygdala (Mahler and Berridge, 2009; Ho and Berridge, 2014). Microinjections were delivered by syringe pump at a rate of $0.5 \mu$ lover $1 \mathrm{~min}$ and the microinjector was left in place for an extra minute to allow for drug diffusion. For the first $2 \mathrm{~d}$ of training, rats were only hooked up to intravenous catheter to allow habituation. Afterward, from days 3-10, an optic fiber and cable were also attached to the head cap to match test conditions for optogenetic rats as described above.

Combined CeA ChR2 excitation + muscimol/baclofen inhibition. To test whether GABAergic inhibition would block CeA ChR2 enhancement of motivation, this group of rats received optogenetic CeA ChR2 excitation combined with pharmacological inhibition of the same CeA sites $(n=4)$. Rats first received microinjections of muscimol/baclofen 15 min before each session from days 1-4. After microinfusion, microinjector tips were removed and replaced by optogenetic fibers secured in place by being screwed on to the cannula guide thread. At the end of each session, optogenetic fibers were removed and replaced by dummy cannulas. On every day, rats were trained with CeA ChR2 stimulation in the two-choice task with identical procedures as for the CeA ChR2 group above. To test whether any CeA inhibition effects on behavior seen on days 1-4 were permanent or state dependent, no muscimol/baclofen microinjections were administered before sessions on days 5-6. Each rat had either fixed portholes throughout all days ( $n=2$ muscimol/baclofen, $n=2$ vehicle rats) or retractable portholes throughout all days ( $n=2$ muscimol/ baclofen, $n=2$ vehicle rats).

\section{Progressive ratio test of breakpoint: does CeA ChR2 amplify effort to obtain cocaine?}

To assess independently whether CeA ChR2 stimulation amplified the intensity of incentive motivation to earn cocaine, a progressive ratio test of instrumental effort was used to obtain a breakpoint measure on 2 successive days. On one day (order counterbalanced across rats), only the laser + cocaine instrumental nose port and outcome was offered $(\mathrm{CeA}$ 


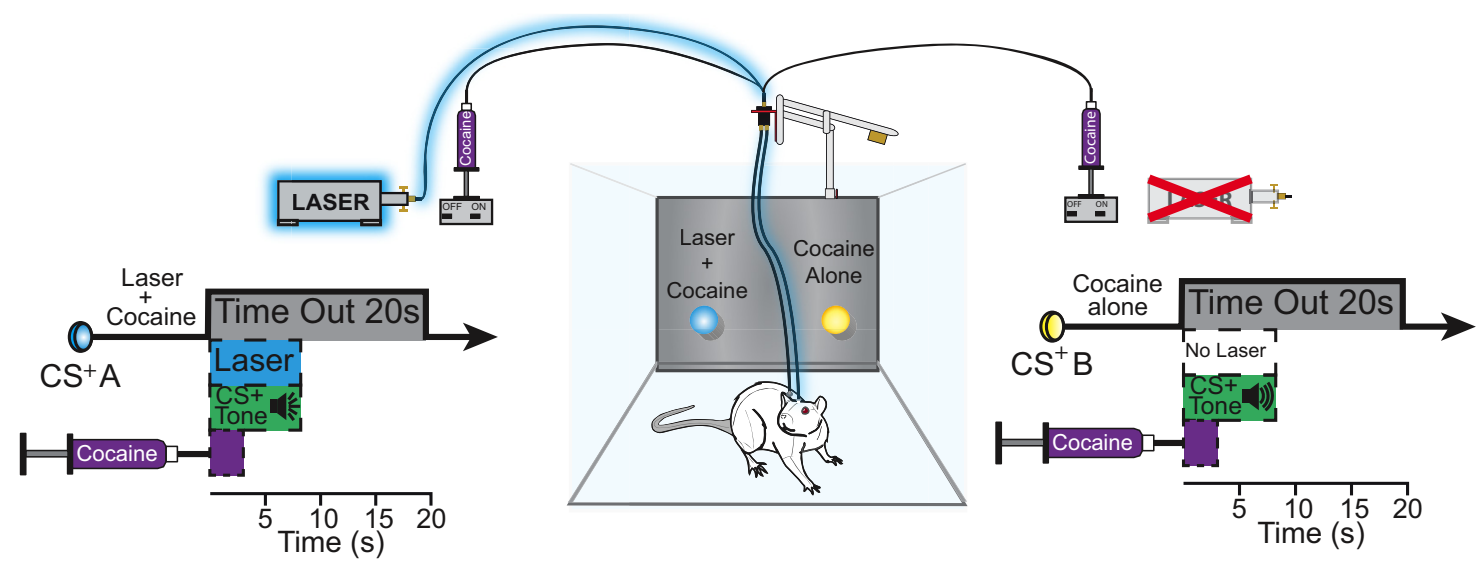

Figure 1. Instrumental two-choice task. Rats instrumentally nose poked into two different ports, first one at a time and then were allowed to choose between the two for the remainder of each session. One port earned a cocaine infusion ( $0.3 \mathrm{mg} / \mathrm{kg}$ in $50 \mu \mathrm{l}, 2.8 \mathrm{~s}$ duration; FR1 schedule) accompanied by a discrete $8 \mathrm{~s}$ tone and additional blue laser stimulation ( $25 \mathrm{~Hz}, 8-10 \mathrm{~mW}, 8 \mathrm{~s}$ ) (laser + cocaine). Nose poking into a second port located on the same wall earned an identical cocaine infusion ( $0.3 \mathrm{mg} / \mathrm{kg}$ in $50 \mu \mathrm{l}, 2.8 \mathrm{~s}$ duration) accompanied by a different $8 \mathrm{~s}$ tone (cocaine alone). Both choices resulted in a 20 s timeout after cocaine infusion.

ChR2: $n=9$ unilateral and $n=3$ bilateral; CeA control virus: $n=5)$. On the other day, only the cocaine alone port and outcome was offered. The alternative nose port was removed each day and replaced with wall inserts. Within each session, the number of nose pokes required to earn the next cocaine infusion $(0.3 \mathrm{mg} / \mathrm{kg})$ was increased after every cocaine reward according to an exponential progressive ratio schedule $(1,2,4,6,9$, $12,15,20,25,32,40,50,62,77,95,118,145, \ldots)$ derived from the formula $\mathrm{PR}=\left[5 e^{(\text {reward number } \times 0.2)}\right]-5$ and rounded to the nearest integer (Richardson and Roberts, 1996; Saunders and Robinson, 2011; Robinson et al., 2014). Each cocaine infusion was followed by a $20 \mathrm{~s}$ timeout identical to that imposed during the instrumental two-choice test.

\section{Laser self-stimulation (CeA laser self-administration without cocaine)}

To investigate more directly whether CeA ChR2 excitation was an independent reinforcer, the same rats from above could earn CeA laser selfstimulation pulses alone by performing new responses in three different situations. In an "active-response" self-stimulation task, rats could earn CeA laser illuminations by simply touching one of two empty water spouts. In a second active response self-stimulation task using an instrumental response more similar to that used in our cocaine self-administration task, drug-naive rats could earn CeA laser illuminations by making a nose poke into a fixed porthole on 2 consecutive days. In a third, "passive response" self-stimulation task, rats could earn CeA laser illuminations by simply going to a particular location or even just remaining in that location.

In the spout self-stimulation active task (spout-touch task), rats were placed into Med Associates operant chambers equipped with 2 novel and empty sipper spouts on the back wall of the chamber positioned $\sim 5 \mathrm{~cm}$ apart. A metal grid floor was wired to close a circuit to detect contacts at each spout. Touching one spout (designated as "active spout"; spout assignment counterbalanced between rats) delivered CeA laser stimulation $(25 \mathrm{~Hz} ; 8-10 \mathrm{~mW}$; FR1 schedule; some rats always earned a $1 \mathrm{~s}$ pulse, $n=6$, and other rats always earned an $8 \mathrm{~s}$ pulse, $n=7$; no auditory cue). The $1 \mathrm{~s}$ pulse was used because it has supported optogenetic selfstimulation in previous studies (Witten et al., 2011; Kravitz et al., 2012). The $8 \mathrm{~s}$ pulse was used for other rats because it was identical in parameters used to amplify motivation for cocaine in our drug self-administration task above. Touching the other available spout produced no consequence and its contacts simply served as a control measure for exploratory touches, general motor activity, or habitual spout investigation. Each self-stimulation test lasted $30 \mathrm{~min}$ and each rat was tested repeatedly on 3 consecutive days.

In the nose-poke self-stimulation active task, procedures were similar to the spout task above, but with portholes rather than two spouts $(n=6)$. The active porthole (arbitrarily assigned) earned either 1 or $8 \mathrm{~s}$ pulses of $8 \mathrm{~mW}, 25 \mathrm{~Hz}$ laser illuminations (pulse duration was counterbalanced across rats, but always the same for an entire $1 \mathrm{~h}$ session on a given day).

In the place-based self-stimulation passive task, a rat could earn realtime CeA laser stimulation simply by going to a particular corner location within a four-corner chamber to trigger a motion detector or simply by making any further movement while remaining in that corner (Robinson et al., 2014). This place-based self-stimulation task was modeled on the original Olds and Milner (1954) demonstration of deep-brain electrode self-stimulation, in which a rat earned electrode stimulation simply by going to a particular corner of a table. The apparatus consisted of a four-corner square Plexiglas chamber $(38 \times 38 \mathrm{~cm})$ with bedding on the floor. A Plexiglas cylinder occluded the center of the chamber $(20 \mathrm{~cm}$ diameter) so that rats were confined to the outer perimeter, where they could perambulate freely to enter or leave any of the four corners of the chamber. Each corner contained an infrared motion detector (Visonic) $46 \mathrm{~cm}$ above the floor that was triggered if the rat entered and by any subsequent movement within the corner. Entry into a designated corner delivered a pulse of CeA ChR2 laser illumination lasting either 1 or $8 \mathrm{~s}$ duration for different rats $(25 \mathrm{~Hz}, 8-10 \mathrm{~mW})$. Exit from that corner always terminated the laser. The same corner was always used for a given individual rat on every session, but different rats were assigned randomly to different corners. Each self-stimulation session lasted $30 \mathrm{~min}$ and each rat received three repeated sessions, one per day.

\section{Switch from laser + cocaine to laser alone: can CeA ChR2 laser maintain responses during drug extinction?}

As a final test of laser self-stimulation, we assessed whether CeA ChR2 stimulation by itself would at least maintain instrumental nose-poke responding after a substantial level of this response already had been well established by laser + cocaine combination. To test this, CeA ChR2 rats from the cocaine self-administration group above $(n=7)$ were retrained for $2 \mathrm{~d}$ on the two-choice task (laser + cocaine vs cocaine alone; FR1 schedule; days 20-21) to reestablish and confirm their nose-poke response. Then cocaine was discontinued from both portholes for 4 successive test days (days 22-25) to convert the task to pure CeA ChR2 laser self-stimulation (now without cocaine: cocaine extinction). On these cocaine extinction days, nose pokes into the original laser + cocaine porthole still earned $8 \mathrm{~s}$ bins of laser alone as before $(8 \mathrm{~s}, 25 \mathrm{~Hz}, 8-10$ $\mathrm{mW}$ ) and both portholes delivered their associated auditory cues, but neither porthole delivered cocaine infusions. In other words, on days $22-25$, rats had a choice between laser alone versus nothing while performing the same instrumental responses that were reinforced previously by cocaine. For the next $3 \mathrm{~d}$ (days 26-28), laser was discontinued in 
addition to cocaine and nose pokes into either port only delivered their associated auditory cues (nothing vs nothing).

\section{Anatomical localization: sites, virus expression, Fos plumes, and localization of function maps}

At the end of behavioral testing, rats were deeply anesthetized with an overdose of sodium pentobarbital (150-200 $\mathrm{mg} / \mathrm{kg}$ ) and transcardially perfused $75 \mathrm{~min}$ after receiving laser. For ChR2 experiments, blue laser (8$10 \mathrm{~mW}$ ) was administered at $25 \mathrm{~Hz}, 8 \mathrm{~s}$ ON $22 \mathrm{~s}$ OFF cycle for $30 \mathrm{~min}$ duration immediately before anesthetization. For halorhodopsin (eNpHR) experiments, constant yellow laser $(8-10 \mathrm{~mW})$ was bilaterally illuminated continuously for $30 \mathrm{~min}$ duration before anesthetization. Brains were stored in $4 \%$ paraformaldehyde, cryoprotected in 30\% sucrose, and sliced at $40 \mu \mathrm{m}$ coronal sections for identification of optic fiber placements and virus expression. Brains were additionally processed for Fos protein expression and for Fos plumes surrounding the illuminated optic fiber (CeA ChR2: $n=$ 5; BLA ChR2: $n=5$; CeA eNpHR: $n=6$ ). Slices were blocked in 5\% normal donkey serum/ $0.2 \%$ Triton-X solution for $30 \mathrm{~min}$ before being incubated for $24 \mathrm{~h}$ in a polyclonal rabbit anti-c-fos IgG primary antibody (Santa Cruz Biotechnology; 1:1000 dilution; lot \#K0415, RRID: AB_2106783), followed $1 \mathrm{~d}$ later by $2 \mathrm{~h}$ in Alexa Fluor 594 donkey anti-rabbit IgG secondary antibody (Life Technologies; 3:1000 dilution; lot \#1668652, RRID: AB_141637) (Faure et al., 2008). Sections were mounted, air-dried, and coverslipped with ProLong Gold anti-fade reagent (Invitrogen). Control virus rats that also received laser illumination before perfusion (total $n=10$; CeA blue laser: $n=4$; BLA blue laser: $n=3$; CeA yellow laser: $n=3$ ) served as controls to compare baseline effects of laser illumination on local Fos plumes (Stujenske et al., 2015). Additional unoperated rats (no surgery; completely naive) served as normal baseline controls to determine spontaneous baseline levels of Fos expression in CeA and BLA $(n=6)$.

Fiber-optic sites, GFP virus expression, and Fos expression was measured using images taken with a Leica microscope (Leica at $10 \times$ and $40 \times$ magnification and marked in Adobe Illustrator (RRID: SCR:014198) on a rat brain atlas (Paxinos and Watson, 2007). For each CeA site, nine images $(3 \times 3$; $10 \times$ magnification $)$ were compiled using Oasis Surveyor software (Objective Imaging; RRID: SCR014433) into one single image centered on the fiber tip and spread/intensity of virus and neuronal Fos expression surrounding the tip was mapped. Our procedure used for measuring Fos plumes surrounding a fiber-optic tip induced by ChR2 photostimulation was modified from Robinson et al. (2014). Immunoreactivity for Fos-like protein was visualized using a fluorescent microscopy filter with an excitation band at 515-545 nm for Fos-positive cells. The number of Fos-expressing cells was counted within successive blocks $(50 \times 50 \mu \mathrm{m})$ along eight radial arms emanating from the fiber-optic tip at $10 \times$ magnification. Counts continued outward along an arm until at least two sequential blocks contained zero Foslabeled cells, which was taken as marking the radius of the Fos plume along that arm. Intensities of Fos elevation in neurons were calculated in terms of percentage change from either of two baselines: (1) inactive virus control baseline: CeA tissue from rats with an optically inactive control virus containing the GFP gene but lacking the ChR2 gene, which received laser illumination before perfusion similarly to ChR2 rats; and (2) normal tissue baseline: CeA or BLA counts of Fos from unoperated control brains of normal rats. Elevations were denoted in increments of $>200 \%$ elevation above the respective two baselines or higher at $>300 \%$ elevation above. Inhibitory suppres- sions were denoted in decrements of $<0.75$ fraction relative to the two baselines (i.e., $>25 \%$ suppressions) and $<0.50$ fractions (i.e., $>50 \%$ suppressions). The local region surrounding a fiber tip that expressed Fos elevation was considered to constitute the local stimulated "Fos plume" and its diameter and volume reflected the extent of local neuronal activation induced by laser illumination in CeA ChR2 rats. Conversely, the local region surrounding a fiber tip that expressed Fos suppression was considered to constitute the local inhibited "Fos anti-plume," with its diameter and volume reflecting the extent to which neuronal activation was suppressed using halorhodopsin. The size of measured stimulated Fos plume was used to assign the scaled size of symbols expressing behavioral consequences in brain atlas maps showing localization of function, in which the color of symbols represented behavioral effects produced at particular sites (see Fig. 3).

For quantification of viral spread around the fiber-optic tip, GFPlabeled cells were counted individually within successive blocks $(50 \times 50$ $\mu \mathrm{m})$ along eight radial arms emanating from the fiber-optic tip at $10 \times$ magnification (Robinson et al., 2014). The number of GFP-labeled cells in each block was counted to assess the intensity of virus expression at each point and to measure the radius of GFP expression along each arm. Intensity of virus infection was mapped as elevations over normal zero baselines.

\section{Statistical analysis}

Results were analyzed in SPSS software (RRID: SCR:002865) using repeated-measures ANOVAs to examine responses for either nose port over training days, followed by $t$ tests for individual comparisons on specific days with Bonferroni corrections. For non-normally distributed data, including all progressive ratio tests, Friedman's two-way ANOVAs were used as nonparametric within-subject tests and Kruskal-Wallis one-way ANOVAs for between-subject tests, followed by Wilcoxon's sign-ranked/Mann-Whitney tests for individual comparisons. Effect sizes for parametric tests were calculated using Cohen's $d$ and for nonparametric tests using $r=\frac{Z}{\sqrt{N_{1}+N_{2}}}$. For all analyses, the significance level was set at $p<0.05$, two-tailed. 
A

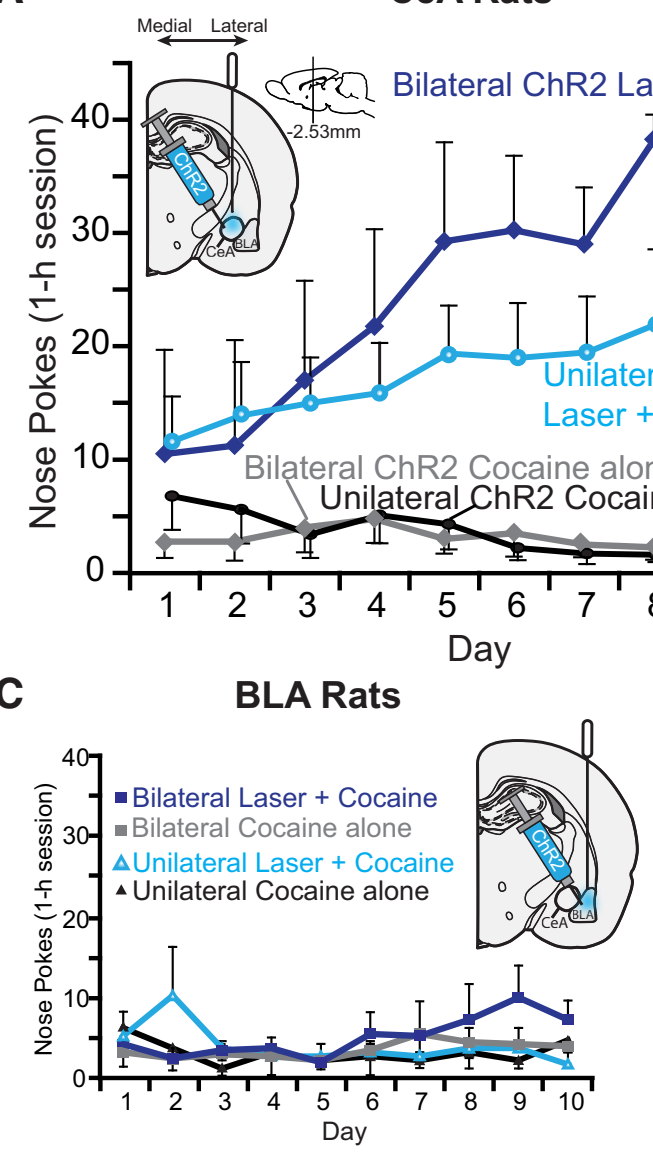

B Cocaine Consumption

(Day 10)

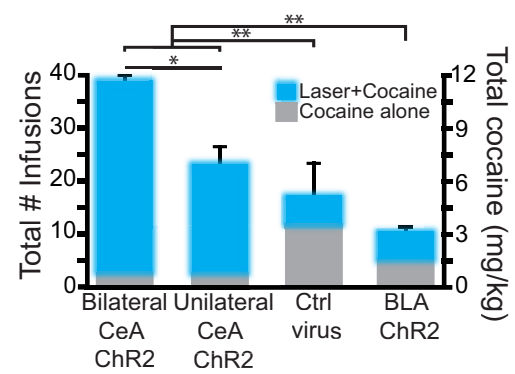

Figure 2. CeA ChR2 stimulation captures choice for a cocaine reward. $A$, Rats exclusively pursued their cocaine reward paired with CeA optogenetic ChR2 stimulation: either unilateral CeA laser illumination (unilateral ChR2 laser + cocaine; solid light blue line with circle symbols) or bilateral CeA illumination (bilateral ChR2 laser + cocaine; solid dark blue line with diamond symbols). The cocaine alone option became relatively ignored (unilateral ChR2 cocaine alone; solid black line with circle symbols; bilateral ChR2 cocaine alone; solid gray line with diamond symbols). $\boldsymbol{B}$, CeA laser resulted in increased cocaine consumption compared with control inactive virus rats and BLA ChR2 rats by the last day of training (day 10 ). $C$, In contrast, basolateral amygdala ChR2 simulation failed to enhance cocaine preference whether bilateral stimulation was earned (bilateral ChR2 laser + cocaine; solid blue lines with blue squares vs bilateral cocaine alone; solid gray lines with gray squares) or unilateral stimulation was earned (unilateral ChR2 laser + cocaine; solid blue lines with blue triangles vs unilateral cocaine alone; solid black lines with black triangles). $\boldsymbol{D}$, Similarly, control inactive virus rats lacking ChR2 gene chose equally between the two cocaine options (laser + cocaine; dashed blue line with gray circles and blue outline vs cocaine alone; dashed black line with gray circles and black outline). (eA ChR2: $n=15$, BLA ChR2: $n=6$, CeA Control virus: $n=5$. Data are shown as mean \pm SEM * $p<0.05,{ }^{* *} p<0.01,{ }^{* * *} p<0.001$.

\section{Results}

Two-choice instrumental task

CeA ChR2 laser pairing made rats prefer their laser + cocaine option by $\sim 2: 1$ over the cocaine alone option as early as the first day in the 2-choice cocaine self-administration task, in which rats could choose between earning either intravenous infusions of cocaine alone or cocaine plus unilateral CeA ChR2 laser illumination (laser + cocaine) (Fig. 1, Movie 1). By the third day, CeA ChR2 preference reached a 4:1 ratio and statistical significance $\left(n=10 ; t_{(9)}=2.52, p=0.03\right.$, Cohen's $d=1.23,95 \% \mathrm{CI}=0.99$ to 18.4) and continued to rise to $10: 1$ or more by the $10^{\text {th }}$ day of FR1 training $\left(t_{(9)}=3.79, p=0.004, d=1.8,95 \% \mathrm{CI}=7.5\right.$ to 30 ; Fig. 2A).

Bilateral delivery of CeA ChR2 laser stimulation ( $n=5$ rats) magnified the strength of laser + cocaine preference even more than unilateral CeA laser $\left(n=10\right.$ rats; laser $\times$ uni/bilateral: $F_{(1,13)}=$ $4.48, p=0.027$; all rats received bilateral CeA ChR2 virus microinjections and bilateral implantation of optic fibers, but a single fiber coupling failed in some rats, resulting in unilateral CeA ChR2 stimulation). For example, on day 1, bilateral CeA ChR2 stimulation produced a 4:1 preference for the laser + cocaine option compared with 2:1 for unilateral stimulation (laser $\times$ uni/ bilateral: $\left.F_{(1,13)}=2.15, p=0.16\right)$. By day 10 , bilateral stimulation produced an 18:1 preference $\left(t_{(4)}=59.0, p=0.000,95 \% \mathrm{CI}=33\right.$ to $37 ; d=1.73$ ) compared with only $10: 1$ for unilateral stimulation (see above; laser $\times$ uni/bilateral: $F_{(1,13)}=5.49, p=0.036$ ). Further, bilateral CeA ChR2 rats took nearly double the amount of cocaine via their laser + cocaine option $(11.4 \mathrm{mg} / \mathrm{kg}$ total cocaine; maximum of 39 infusions per day on days 6-10) compared with unilateral rats $(7 \mathrm{mg} / \mathrm{kg}$ total cocaine; 23 infusions on day 10) $\left(t_{(12)}=2.7, p=0.019,95 \% \mathrm{CI}=-8.8\right.$ to $\left.-1 ; d=-2.34\right)$.

In contrast, rats with ChR2 virus in BLA failed to develop any consistent preference between laser + cocaine versus cocaine alone $\left(n=6 ; F_{(1,5)}=4.253, p=0.095 ;\right.$ Fig. $\left.2 C\right)$ and did not differ from inactive virus control rats in random laser + cocaine preference $\left(F_{(1,9)}=0.003, p=0.96\right)$. Therefore, BLA ChR2 rats chose more or less equally between the two options and were significantly different from CeA ChR2 rats, which preferred laser + cocaine $\left(F_{(1,17)}=11.4, p=0.004\right)$. CeA ChR2 rats (both bilateral and unilateral) also consumed more total cocaine overall on day 10 than did BLA ChR2 rats (29 vs 9 total infusions or $3 \mathrm{mg} / \mathrm{kg}$ total cocaine; $t_{(18)}=3.54, p=0.002,95 \% \mathrm{CI}=2.42,9.5$; Fig. $2 B$ ). Total nose-poke responses (laser + cocaine and cocaine alone combined) by BLA ChR2 rats were actually less than control virus 
rats $\left(F_{(1,9)}=33.6, p=0.000\right)$. Within BLA ChR2 rats, 4 rats earned bilateral stimulation and 2 rats earned unilateral stimulation, but these BLA ChR2 bilateral and unilateral stimulation conditions did not differ in outcome $\left(F_{(1,4)}=0.122, p=0.74\right)$, nor was there any interaction between port preference and bilateral versus unilateral stimulation condition $\left(F_{(1,4)}=0.28, p=\right.$ $0.63)$.

CeA inactive virus control rats with illuminated fiber optics in CeA but infected with optically inactive GFP virus that lacked the ChR2 gene failed to develop any consistent preference for their laser + cocaine option over cocaine alone and continued to choose equally between the two options for all $10 \mathrm{~d}\left(n=5 ; F_{(1,4)}=0.77, p=\right.$ 0.44; Fig. $2 D$ ). As a result, inactive virus control rats (choosing randomly) differed from all CeA ChR2 rats (which preferred laser + cocaine $)\left(F_{(1,19)}=6.52, p=0.02\right)$. For example, on day 10 , inactive virus rats poked less at their laser + cocaine port than either unilateral or bilateral CeA ChR2 rats $\left(t_{(19)}=2.6, p=0.01, d=\right.$ $1.79,95 \% \mathrm{CI}=-33.6$ to -3.4$)$ and poked more at their cocaine alone port than CeA ChR2 rats $\left(t_{(17)}=3.1, p=0.006, d=1.4\right.$, $95 \% \mathrm{CI}=3$ to 15.6$)$. However, overall, inactive virus rats consumed less cocaine than CeA ChR2 rats $(5 \mathrm{mg} / \mathrm{kg}$ cocaine total in 17 infusions vs $7 \mathrm{mg} / \mathrm{kg}$ unilateral CeA ChR2 and $11.4 \mathrm{mg} / \mathrm{kg}$ bilateral; $F_{(2,22)}=6.35, p=0.002$; Fig. $\left.2 B\right)$.

Total responding for cocaine on the last day (laser + cocaine and cocaine alone) did not differ across phases of the estrus cycle either at the beginning (unilateral CeA rats: $F_{(1,4)}=2.35, p=0.2$; bilateral CeA rats: $F_{(1,3)}=0.6, p=0.5$; BLA rats $F_{(1,3)}=0.01, p=$ 0.92 ) or at the end (unilateral rats: $F_{(1,4)}=0.02, p=0.89$; bilateral CeA rats: $F_{(1,3)}=0.6, p=0.5$; BLA rats $\left.F_{(1,3)}=0.01, p=0.92\right)$ of training for any rats.

\section{Fos plumes versus virus infections: Fos plume sites determine localization of function}

ChR2 Fos plumes were much smaller than CeA or BLA zones of virus infection, so the mean Fos plume radius $(0.2 \mathrm{~mm}$ outer radius of doubled elevation) was used to set the size of individual map symbols in Figure 3. Histological analysis of GFP expression revealed zones of ChR2 virus infection averaging $\sim 1.8 \mathrm{~mm}$ diameter in either CeA or BLA, forming an approximately spherical volume of $2.6 \mathrm{~mm}^{3}$ and often filling most of either CeA (CeA volume is $2.4 \mathrm{~mm}^{3}$ ) or BLA. In CeA, optic fiber tips were concentrated mostly in the caudal and middle AP zones of CeA (Fig. 3) and were distributed mediolaterally in approximately equal numbers in the medial subdivision of CeA (CeM; $n=5)$, lateral subdivision of CeA ( $\mathrm{CeL} ; n=5)$, and capsular subdivision of CeA $(\mathrm{CeC} ; n=4)$. In BLA, sites were scattered throughout midrostral BLA extent and more laterally. Mapping of CeA fiber sites that were behaviorally effective in the two-choice task revealed that sites in CeM subdivision and in CeL comparably support CeA ChR2 induction of a 25:1 preference ratio for laser + cocaine (Fig. 3). Two sites in CeC capsular nucleus slightly dorsal to CeM or $\mathrm{CeL}$ were also effective at amplifying motivation for cocaine. In contrast, BLA sites were generally ineffective at enhancing cocaine pursuit. In fact, a few BLA sites appeared to produce negative avoidance of their laser-paired cocaine option by at least 3:1 to $5: 1$ ratios (though not significant for the entire BLA ChR2 group) and further actually suppressed total cocaine intake slightly compared with inactive virus controls $\left(F_{(1,9)}=33.6\right.$, $p=0.000)$.

Laser illumination of fibers in CeA ChR2 rats produced 0.02 $\mathrm{mm}^{3}$ Fos plumes of elevated expression surrounding the fiberoptic tips compared with either control levels measured in inactive virus rats $\left(0.14 \mathrm{~mm}\right.$ radius; $F_{(1,6)}=19.2, p=0.000,95 \% \mathrm{CI}=$
-0.173 to -0.063$)$ or CeA tissue from normal unoperated rats $\left(F_{(1,3)}=15.6, p=0.001,95 \% \mathrm{CI}=-0.189\right.$ to -0.061$)$. Fos plumes contained a tiny $<0.01 \mathrm{~mm}^{3}$ center of intense $>300 \%$ Fos elevation ( $3.4 \pm 0.2$ Fos + neurons $)$, compared with illumination in control rats with inactive virus $(0.0114 \pm 0.11$ Fos + neurons) (also $>300 \%$ above CeA levels in unoperated control brains: $0.0042 \pm 0.065$ Fos + neurons). The intense center was surrounded by a larger $0.02 \mathrm{~mm}^{3}$ volume outer plume of less-intense $200 \%$ Fos elevation, which was arrowhead shaped and extended farthest 0.21 $\mathrm{mm}$ ventrally beneath the illuminated tip (range $0.07=0.2 \mathrm{~mm}$ in all directions) and elevation declined from 150\% toward baseline within $0.2-4 \mathrm{~mm}$ below the fiber-optic tip (Fig. 4). CeA ChR2 laser illumination induced Fos plumes of similar sizes regardless of whether the optic fiber was placed in the CeM, CeL, or CeC subdivisions $\left(F_{(2,5)}=0.373, p=0.706\right)$. In contrast, laser produced no Fos plumes in control inactive virus rats $(p=1.0,95 \% \mathrm{CI}=-0.08$ to 0.07).

It seems noteworthy that the average Fos plume produced by CeA ChR2 laser stimulation was $<\sim 2 \%$ of the volume of average CeA virus infection (Fig. 4). Further, each $0.02 \mathrm{~mm}^{3}$ Fos plume corresponded to only $\sim 1 \%$ of the entire anatomical volume of CeA. This observation suggests that optogenetic illumination of ChR2 directly modulates Fos expression of neurons within a tiny fraction of CeA and a much smaller anatomical zone than the total range of virus infection, but is still sufficient to induce powerful behavioral effects; this was true whether sites were in CeL or CeM. Further suggesting that the small Fos plumes were more important than total virus infection, the size of larger volumes of virus infection did not correlate with degree of laser + cocaine preference (Spearman's $\rho, r_{\mathrm{s}}=0.018, p=0.969$ ).

Laser illumination of fibers in BLA ChR2 rats produced similarly small $0.03 \mathrm{~mm}^{3}$ Fos plume of elevated expression surrounding the fiber-optic tips compared with control levels measured in inactive virus rats $\left(.16 \mathrm{~mm}\right.$ radius; $F_{(1,8)}=22.9, p=$ $0.000,95 \% \mathrm{CI}=0.2$ to 0.6$)$ and compared with BLA tissue from normal unoperated rats $\left(0.25 \mathrm{~mm}\right.$ radius; $F_{(1,7)}=9.31, p=0.003$, $95 \% \mathrm{CI}=0.8$ to 1.27 ). Similar to CeA ChR2 plumes, BLA ChR2 Fos plumes also contained a smaller $0.01 \mathrm{~mm}^{3}$ center of intense $>300 \%$ Fos elevation (26.5 \pm 8.6 Fos + neurons $)$ over Fos levels in control rats with inactive virus (6.5 \pm 3.5 Fos + neurons) (Fig. 5).

Halorhodopsin in CeA, when illuminated by yellow laser, suppressed Fos expression by at least 25\% below control levels, creating $0.016 \mathrm{~mm}^{3}$ inhibitory plumes with $\sim 0.25 \mathrm{~mm}$ radius (which we call anti-plumes). These Fos levels were only $<0.75$ of control levels (i.e., $>25 \%$ suppression) compared with baselines of either inactive virus control rats that also received yellow laser in $\mathrm{CeA}\left(F_{(2,9)}=60.9, p=0.000,95 \% \mathrm{CI}=0.21\right.$ to 0.13$)$ or of normal unoperated rats that received no laser $(0.14 \mathrm{~mm}$ radius; $F_{(2,8)}=22.9, p=0.001,95 \% \mathrm{CI}=0.21$ to 0.1$)$. Halorhodopsin anti-plumes also contained smaller $0.003 \mathrm{~mm}^{3}$ centers of even more intense suppression to levels between 0.1 to 0.5 of inactive virus baseline levels (i.e., $>50 \%$ suppression to $>90 \%$ suppression) and these centers had nearly a $0.1 \mathrm{~mm}$ radius $(1 \pm 0.39$ Fos + neurons) compared with normal unoperated tissue $(11 \pm 1$ Fos + neurons; Fig. 4). Therefore, halorhodopsin illumination by yellow laser produced the opposite neurobiological effects on local neuronal Fos expression than ChR2 illumination by blue laser in CeA. The opposite effects of illuminating halorhodopsin versus ChR2 confirm that these manipulations have the opposite neurobiological effects on neuronal Fos expression in CeA, even though Fos changes do not always correspond to electrical depolarization versus hyperpolarization. The comparable sizes of ChR2 Fos plumes versus halorhodopsin Fos anti-plumes further 


\section{CeA ChR2 and BLA ChR2 Sites}

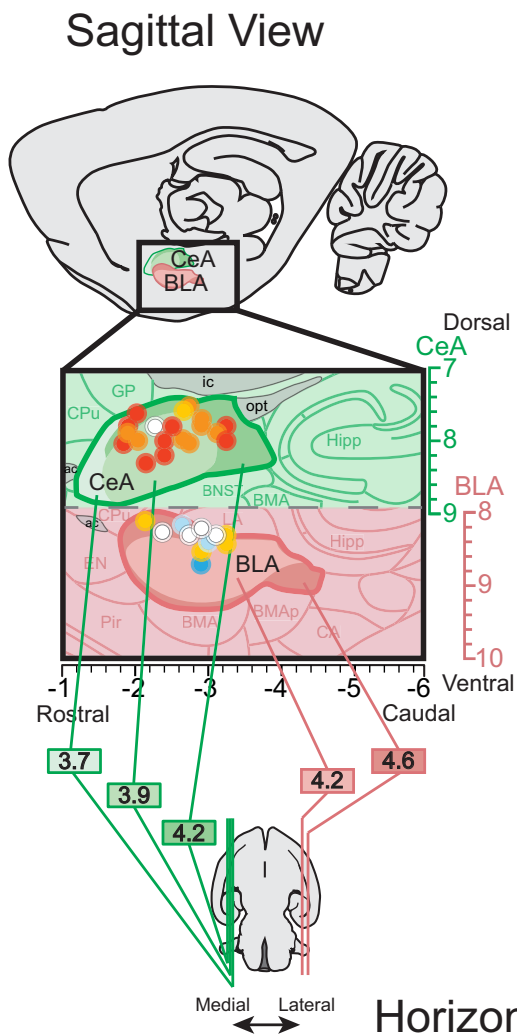

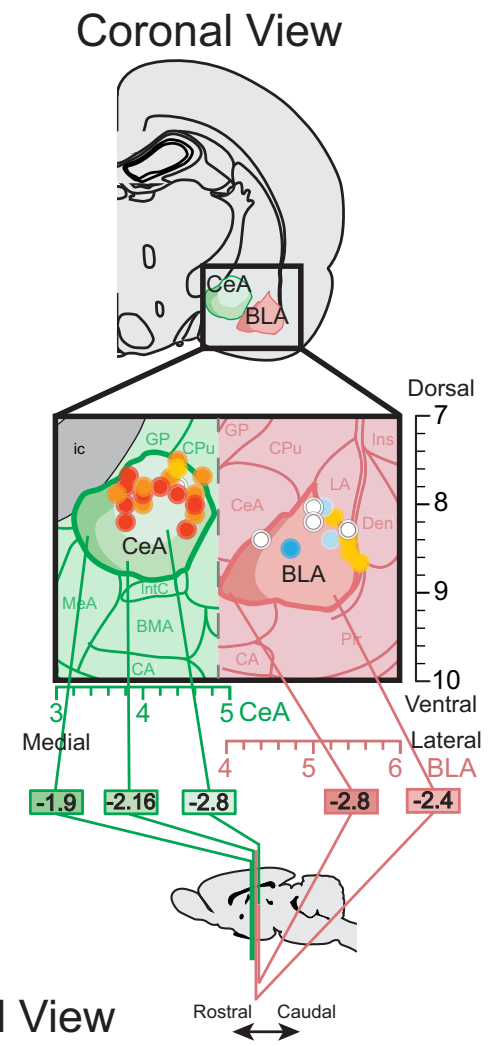

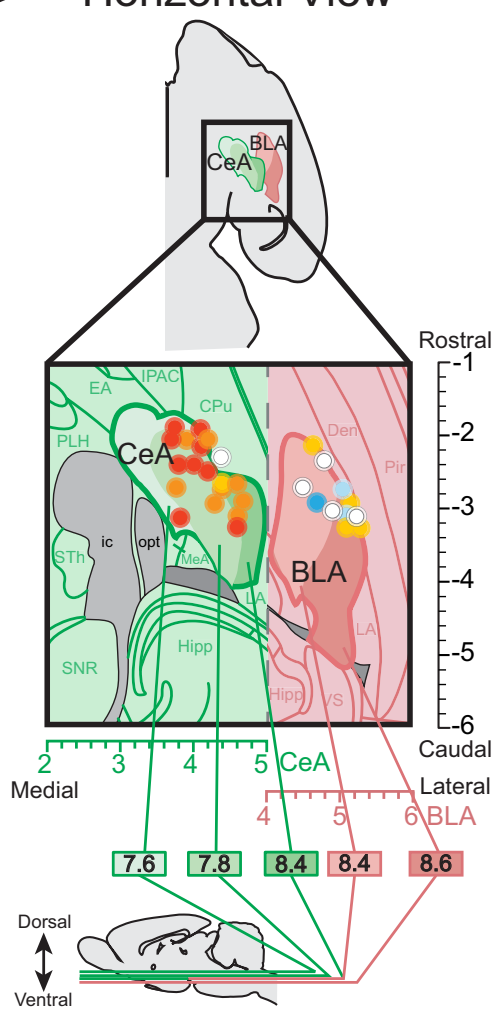

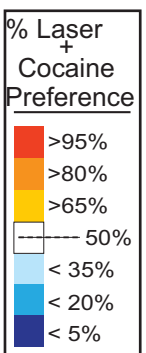

\section{.}

\section{.}

indicate that both manipulations primarily affect neurons within a $0.1 \mathrm{~mm}$ (center) to $0.3 \mathrm{~mm}$ (outer plume) radius of the fiber-optic tip even if virus expression or light extends further from the tip. That relatively small radius suggests that infected neurons may have a threshold of illumination required to alter Fos expression, which is met only by neurons lying within that radius with these laser parameters.

\section{Nose-poke duration and consummatory responses to porthole} Beyond making CeA ChR2 rats choose laser + cocaine far more often than cocaine alone, laser pairing in CeA ChR2 rats also tripled the duration of each nose poke that they made into that laser + cocaine porthole (3s) compared with poke duration in the alternative cocaine alone porthole (1 s) $\left(t_{(8)}=4.92, p=0.001,95 \% \mathrm{CI}=\right.$ 0.88 to $2.44 ; d=2.374)$. By comparison, inactive virus control rats made pokes of merely $1 \mathrm{~s}$ durations in both their laser + cocaine and alternative portholes $\left(t_{(11)}=\right.$ 2.91, $p=0.014,95 \% \mathrm{CI}=-2.9$ to -0.4 ; $d=3.5$ ). This ChR2 duration extension of the consummatory nose poke for laser + cocaine was found in both bilateral and unilateral CeA ChR2 rats ( $p=0.396,95 \%$ $\mathrm{CI}=-0.47$ to 1.72 ). The prolongation of nose-poke duration appeared related to the induction of oral consummatory behaviors emitted during the nose poke toward their metal laser-paired porthole.

Specifically, laser pairing made CeA ChR2 rats display novel active consummatory reactions of nibbling and biting of the metal rim of their laser-paired porthole, in addition to perseverative sniffs that most rats commonly display toward Pavlovian cocaine cues (Movie 2). During nibbles, a rat's upper teeth at least contacted the metal rim for a brief moment $(<0.5 \mathrm{~s})$, sometimes repeatedly within 1-2 s. In bites, a CeA ChR2 rat's upper and lower incisors closed completely on the outer rim of its laser + cocaine porthole, remaining closed for up to $1 \mathrm{~s}$. A bite often was accompanied by a strong pulling motion of the head and neck away from the wall, which sometimes actually succeeded

\section{$\leftarrow$}

pairing at that site, expressed as percentage of choice over cocaine alone during the last two sessions of the two-choice test. Sizes of symbols represent the average Fos plume diameter observed in CeA ChR2 and BLA ChR2 after laser stimulation (inner plumes scaled to represent Fos plume elevations $>200 \%$ above control virus baseline Fos levels 0.2 mm radius; and outer plumes represent Fos plume elevations $>150 \%$ above baseline Fos levels $\sim 0.3 \mathrm{~mm}$ radius).
Figure 3. Localization of function maps. Maps show behavioral effects in the two-choice task of corresponding amygdala sites in Figure 2. At each sagittal, coronal, and horizontal view, the outermost boundaries of CeA and BLA are shown at varying medial/lateral levels (sagittal view; ML 3.7 to $4.6 \mathrm{~mm}$ from bregma), rostral/caudal levels (coronal view; AP -1.9 to $-2.8 \mathrm{~mm}$ from bregma), or dorsal/ventral levels (horizontal view; DV -7.6 to $-8.6 \mathrm{~mm}$ from bregma). The unique boundaries at each leve within (eA or BLA are shown as lighter to darker shades (shades of green for (eA and shades of pink for BLA). CeA but not BLA sites of fiber optics enhanced preference for cocaine. Colors depict the preference intensity for laser + cocaine caused by ChR2 lase 
CeA ChR2 Virus

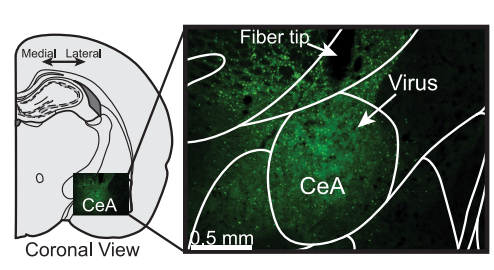

Overlay: CeA ChR2 Virus + Fos
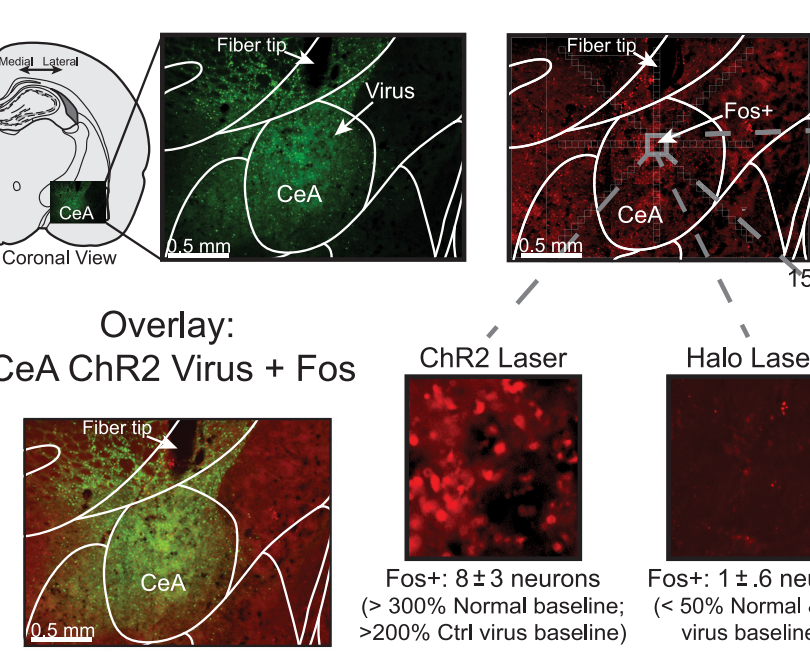

CeA ChR2 Fos

Normal Tissue Baseline
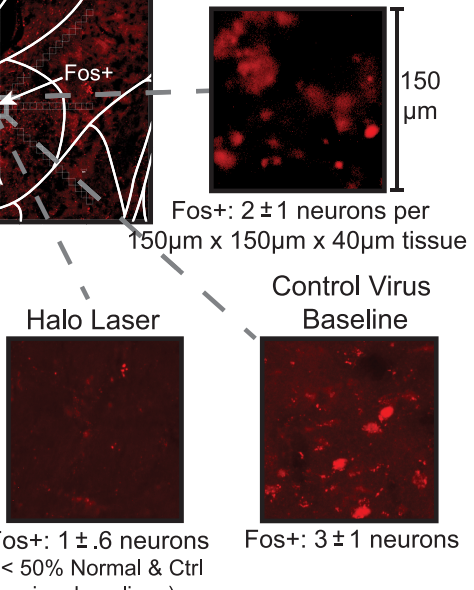

Control Virus
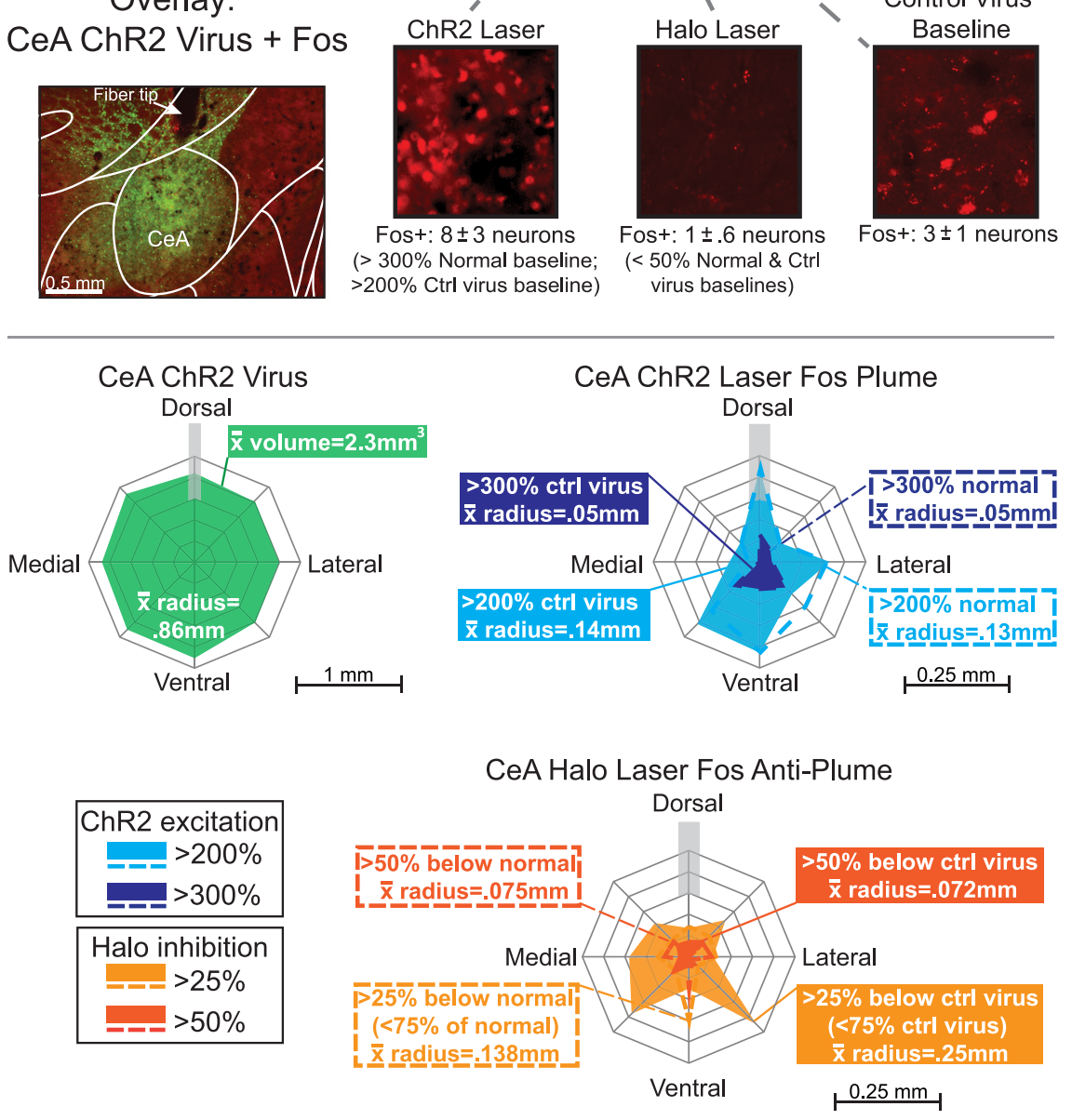

CeA Virus vs. Fos Plume Spread

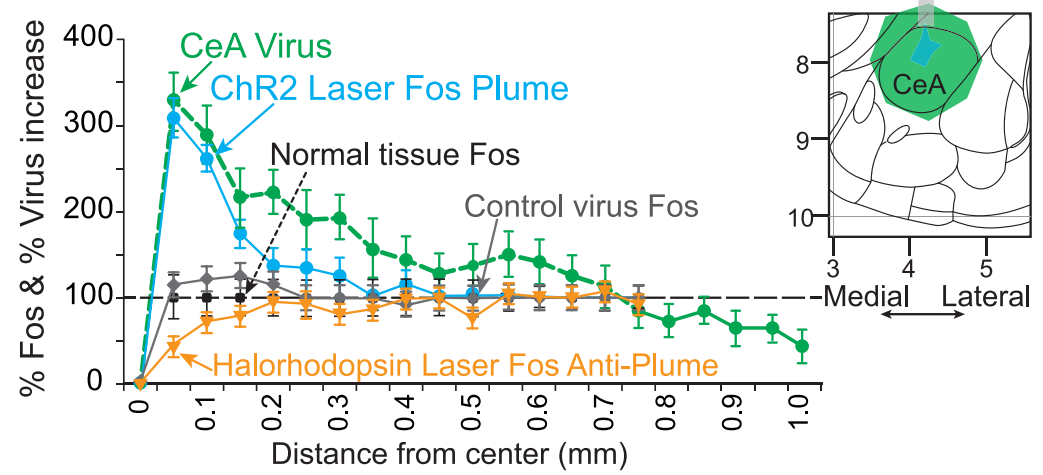

Figure 4. Anatomical spread of laser-induced CeA Fos plumes and of virus expression. Top, Photomicrographs of CeA show green ChR2 virus expression (CeA ChR2 virus), red Fos protein immunohistochemistry expression stimulated around an fiber-optic tip, induced by laser illumination in a (eA ChR2 rat before euthanasia (CeA ChR2 laser Fos), and overlay photo combining GFP virus infection plus laser-induced Fos plume in the same CeA ChR2 rat (overlay: CeA ChR2 virus + Fos). Magnifications of $150 \mu \mathrm{m} \times 150$ $\mu \mathrm{m} \times 40 \mu \mathrm{m}$ CeA tissue from immediately below the fiber-optic tip depict sample numbers of Fos-expressing neurons in each condition, which were used to help determine the percentage Fos intensity within local plumes induced by laser stimulation. in moving the metal porthole rim a millimeter or so further out from its anchored position. Approximately $80 \%$ of $\mathrm{CeA}$ ChR2 rats nibbled and/or bit their laser + cocaine retractable porthole compared with $0 \%$ of inactive virus control rats and $0 \%$ of BLA ChR2 rats (Fig. 6A). Nibbles and bites were specifically directed to the laser + cocaine porthole because CeA ChR2 rats were never observed to nibble or bite their cocaine alone porthole, even when they made nose pokes into it. Bites and nibbles toward the laser-paired porthole were observed in CeA ChR2 rats that received unilateral laser illumination $(n=$ $1)$ or bilateral laser illumination $(n=4)$.

$\leftarrow$

Groups include normal tissue baseline (spontaneous Fos in CeA of a normal unoperated rat), control virus baseline (a control rat with inactive virus in $\mathrm{CeA}$, after local blue laser illumination), CeA ChR2 laser Fos plume (a CeA ChR2 rat after blue laser illumination), and CeA halorhodopsin laser (a CeA halorhodopsin rat after yellow laser illumination). For each magnification, the mean number \pm SE of Fos ${ }^{+}$neurons per $150 \mu \mathrm{m} \times$ $150 \mu \mathrm{m} \times 40 \mu \mathrm{m}$ tissue sample for that entire condition's group at same anatomical position within CeA plume (relative to fiber tip) is also shown. These numbers were used to calculate the percentage change in local Fos expression at various positions within Fos plume and to establish the borders of laser-induced Fos plumes). Middle, Map on left (CeA ChR2 Virus) shows average mean radius of ChR2 virus spread in CeA from center of infection (virus radius $=0.86 \mathrm{~mm}$, spherical volume $=2.63 \mathrm{~mm}^{3}$ ). Blue map on right shows laser-induced CeA ChR2 Fos plume (light blue outer zone is the extent of $>200 \%$ Fos elevation induced by laser illumination (measured relative to baseline levels in control inactive virus rats after similar (eA laser; $\sim 0.14 \mathrm{~mm}$ mean radius). Dark blue inner zone is the extent of higher $>300 \%$ Fos elevation over inactive virus levels. Note that Fos plumes may extend maximally straight below fiber-optic tip, reflecting downward path of light beam $(0.35 \mathrm{~mm})$. Dotted blue lines indicate similar ChR2 elevations relative to normal CeA tissue baselines (illumination of control virus may induce mild Fos elevation over normal tissue levels, perhaps due to heat, virus infection, or surgical penetration). Yellow map below shows Fos suppression caused by yellow laser illumination in CeA halorhodopsin rats (i.e., anti-plume). Outer solid orange plume is the extent of $>25 \%$ Fos suppression (i.e., Fos reduction to $<75 \%$ control level) compared with control inactive virus condition after yellow laser (0.25 $\mathrm{mm}$ mean radius). Inner solid dark orange plume shows zones of more intense $>50 \%$ Fos suppression over inactive virus levels ( $0.072 \mathrm{~mm}$ mean radius). Dotted lines depict zones of suppression compared with normal baseline tissue. Bottom, Quantitative comparison of virus infection versus Fos elevation intensity as a function of distance beneath center of fiber-optic tip. Fos is plotted as percentage change from normal tissue Fos baseline (100\%) (CeA ChR2 laser Fos plume: blue circles and solid blue lines; halorhodopsin laser Fos: orange downward triangles and solid orange lines; control virus Fos: solid gray diamonds). ChR2 GFP virus intensity is plotted as a percentage change from uninjected tissue (baseline $=0+1$; (eA virus: green circles with green dashed line). All data are shown as mean \pm SEM. Note that Fos elevation falls from peak levels more rapidly with distance than ChR2 virus infection, perhaps reflecting thresholds of light intensity needed to induce Fos in infected neurons. 


\section{BLA ChR2 Virus + Fos}

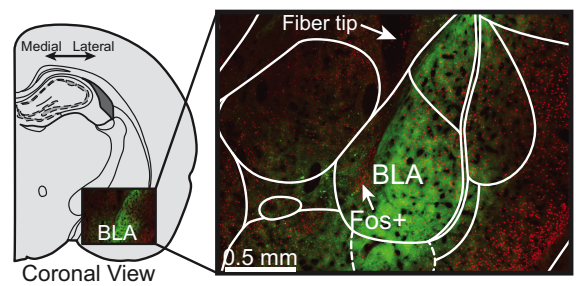

BLA ChR2 Laser Fos Plume

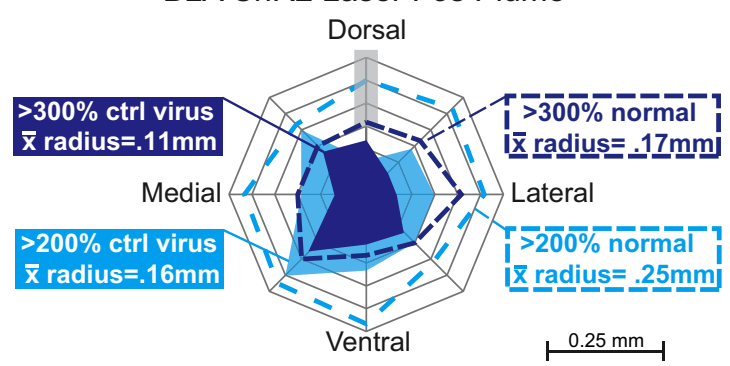

Figure 5. Photomicrograph showing BLA ChR2 Fos protein immunohistochemistry and virus expression in BLA rats similar to Figure 4 around an optic fiber tip, induced by laser illumination before euthanasia (red $=$ Fos, green $=$ ChR2 GFP virus). Outer solid light blue plume is the $>200 \%$ elevation in Fos plume expression relative to control inactive virus condition after similar BLA laser ( $0.16 \mathrm{~mm}$ mean radius). Inner solid dark blue plume shows $>300 \%$ Fos elevation over inactive virus levels $(0.11 \mathrm{~mm}$ mean radius). Dotted lines indicate Fos elevations calculated relative to normal BLA tissue baseline (spontaneous Fos baseline in BLA of unoperated rats).

Actual intoxication with cocaine emerged as a further facilitating or necessary factor for CeA ChR2 consummatory bites and nibbles of the laser-paired retractable porthole: For example, bites and nibbles often did not emerge until the second half of a $60 \mathrm{~min}$ session for CeA ChR2 rats, after the rat had already consumed $\sim 1.5-3.3 \mathrm{mg} / \mathrm{kg}$ cocaine (bites during first half vs second half of session: $t_{(4)}=3.68, p=0.02,95 \% \mathrm{CI}=-16.1$ to -2.3 ; $d=$ $-3.5)$. Some rats that had previously bitten their porthole late in a session subsequently emitted a few bites in the first half of a session on following days, but still tended to emit most bites later in the session (bites during first half vs second half of session: $t_{(4)}=3.8, p=0.02,95 \% \mathrm{CI}=-13.4$ to $\left.-2.2 ; d=-3.8\right)$.

Finally, it also appeared necessary that the porthole actively moved in and out of the chamber because only moving or retractable portholes elicited bites and nibbles from CeA ChR2 rats when paired with laser $(n=5)$, not fixed or immovable nose ports that remained constantly in the chamber $(n=10)$ (bites: $F_{(1,9)}=6.5, p=0.04$; nibbles: $\left.F_{(1,9)}=9.0, p=0.02\right)$. Fixed portholes failed to elicit consummatory bites even when paired with bilateral laser stimulation in CeA ChR2 rats $(n=1)$. Pavlovian cue features are known to be important as unconditioned reward features in determining a conditioned response; for example, when a rat responds to another rat that predicts food with prosocial behaviors (Timberlake and Grant, 1975), but to a rolling ball bearing that predicts food with predatory pounces (Timberlake et al., 1982). Therefore, the sudden appearing and disappearing features of the moving porthole, its cocaine reinforcement and its associative pairing with CeA ChR2 laser stimulation all likely combined together to produce the consummatory bites emitted toward the metal object. Still, a retractable porthole only elicited bites here when it had laser + cocaine status and the same CeA ChR2 rats never bit their retractable cocaine alone porthole. Fi- nally, inactive control virus rats and BLA ChR2 rats never displayed bite or nibble consummatory responses, not even to a retractable cocaine porthole paired with laser $\left(F_{(2,7)}=32.2, p=\right.$ 0.000; Fig. $6 B, C)$.

Nibble or bite consummatory responses toward a metal cocaine cue by rats have never been reported before to our knowledge. Instead, rats are reported typically to emit approach and sniff responses toward a Pavlovian light, location, or object CS for cocaine in autoshaping or sign-tracking studies, but not to bite or nibble the CS object with mouth or teeth (Kearns and Weiss, 2004; Uslaner et al., 2006). Instead, only food-associated CSs are known to evoke nibbles and bites as consummatory responses (Tomie et al., 1989; Mahler and Berridge, 2009; DiFeliceantonio and Berridge, 2012). We note that CeA ChR2 stimulation similarly increased consummatory bites and nibbles of a sucroseassociated metal lever paired with laser in our earlier study (Robinson et al., 2014). Bites and nibbles of the cocaine laserpaired cue here might reflect ingestive incentive motivation or, conceivably, a different CeA ChR2-induced motivation such as predation or aggression or some unspecified incentive attractiveness that made the metal porthole more able to elicit the urge to bite, nibble, and orally grasp.

In contrast, control and BLA rats always merely sniffed their portholes, the more typical consummatory response to a cocaine cue (Kearns and Weiss, 2004; Uslaner et al., 2006). CeA ChR2 rats also emitted consummatory sniffs toward their portholes (both fixed and retractable ports) in addition to nibbles and bites and, in fact, emitted twice as many sniffs to their laser + cocaine porthole as control inactive virus rats did toward either porthole (mean + SEM: $5 \pm 1$ vs $2 \pm 0.8$ sniffs; $t_{(11)}=3.22, p=0.008,95 \%$ $\mathrm{CI}=0.85$ to $4.5 ; d=1.82)$. CeA ChR2 rats also emitted $\sim 6$ times more sniffs to their laser + cocaine porthole than to their cocaine alone porthole $\left(t_{(8)}=6.83, p=0.000,95 \% \mathrm{CI}=1.5\right.$ to $3 ; d=$ $1.45)$. Even among rats with retractable portholes, sniffs were $\sim 2$ times greater to their laser + cocaine porthole than to their cocaine-alone porthole $\left(t_{(3)}=3.3, p=0.04,95 \% \mathrm{CI}=1.0\right.$ to 4.1 ; $d=2.36$; Fig. $6 D$ ). Therefore, CeA ChR2 pairing potentiated sniffing in addition to creating novel bites and nibbles as consummatory response and enhanced responses were always directed specifically toward the laser + cocaine porthole.

\section{CeA ChR2 perseveration during $20 s$ timeout after cocaine}

As soon as a cocaine infusion actually began, control and BLA rats typically stopped making frequent nose pokes into the porthole that they had chosen (randomly overall; $F_{(1,5)}=2.3, p=0.19$ ), but CeA ChR2 rats perseverated with longer pokes into their laser + cocaine porthole that continued during an infusion and even afterward during the $20 \mathrm{~s}$ timeout, when no further cocaine could be earned $\left(F_{(1,13)}=8.9, p=0.01\right)$. For example, CeA ChR2 rats in this sense wasted $50 \%$ more instrumental nose pokes than inactive virus control rats, making pokes that could earn nothing during timeouts on the final $4 \mathrm{~d}$ of training ( $57 \%$ vs $38 \%$ of total nose pokes in each session were made during the $20 \mathrm{~s}$ timeout; $\left.F_{(2,15)}=4.36, p=0.03\right)$. CeA ChR2 perseveration after infusion was shown by both bilateral and unilateral CeA ChR2 rats $\left(F_{(1,13)}=\right.$ $0.29, p=0.6)$.

\section{Loss of CeA function: optogenetic CeA inhibition does not alter choice, but pharmacological CeA inhibition abolishes cocaine pursuit and laser preference}

In the inhibitory or loss of function group, CeA halorhodopsin rats that had $8 \mathrm{~s}$ illuminations of constant yellow CeA laser (592 $\mathrm{nm}, 8-10 \mathrm{~mW})$ paired with one of two cocaine options $(n=7)$, 
suppressing Fos to $10-50 \%$ normal levels within a $0.25 \mathrm{~mm}$ anti-plume radius, did not alter preference and simply chose equally between the two cocaine options when given a choice $\left(F_{(1,6)}=0.27, p=\right.$ 0.62; Fig. $7 A)$. However, overall cocaine consumption appeared marginally reduced for CeA halorhodopsin rats, a suppression that became significant if we raised the criterion for control rats from 5 infusions per day for $3 \mathrm{~d}$ to 6 infusions per day for $3 \mathrm{~d}$ (eliminating one low outlier from inactive virus control rats and leaving a control $\left.n=2 ; F_{(1,7)}=10.5, p=0.01\right)$, but not if we dropped all inclusion criteria $\left(F_{(1,8)}=1.7, p=0.23\right)$. Applying the stricter inclusion criterion, halorhodopsin rats took only approximately half as much cocaine as control rats on day 1 , $\left(t_{(7)}=4.3, p=0.003,95 \% \mathrm{CI}=-21\right.$ to $-6 ; d=-3.02)$ and were still taking less on day $5\left(t_{(7)}=3.5, p=0.01,95 \% \mathrm{CI}=\right.$ -39 to -7.5 ; $d=-3.7)$. However, turning the yellow laser on for the entire 60 min session on day 11 did not further alter that pattern or induce any further suppression of intake $\left(t_{(7)}=1.3, p=0.23,95 \% \mathrm{CI}-39\right.$ to 11$)$.

\section{CeA inhibition by GABAergic microinjections}

In contrast, rats that received pharmacological inhibition of $\mathrm{CeA}$ via bilateral microinjections of a muscimol/baclofen mixture from day 1 of training nearly completely failed to self-administer cocaine once they were connected to head-cap cables on the third day (cables were needed for laser optic fiber connections in optogenetic studies and so were added here to keep conditions similar even though no laser was given to the microinjection-only group). On the first $2 \mathrm{~d}$ of training, CeA muscimol/baclofen rats were not connected to head cables and did self-administer cocaine. On the first day, muscimol/baclofen rats had lower cocaine self-administration levels than vehicle control rats, though this was not significant $\left(t_{(6)}=2.4, p=0.05\right)$. However, on the second no-cable day, consumption levels did not differ statistically $\left(t_{(6)}=0.14, p=0.89\right)$. A closer look at individuals revealed that 2 of $6 \mathrm{CeA}$ muscimol/baclofen rats began to robustly selfadminister 3-5 daily infusions on the first day, which rose to 7-11 on the second day, whereas 3 other CeA muscimol/baclofen rats remained at $0-1$ infusions on both days (control vehicle rats all consumed 5-15 infusions on both days). However, beginning on day 3 , once head caps were connected to fiber-optic cables for all rats, CeA muscimol/baclofen microinjections apparently combined with the additional challenge of mild head tension from head cables nearly completely prevented any cocaine self-administration: 0 or 1 infusion for all CeA muscimol/baclofen rats versus, on average, 12 infusions for control CeA vehicle microinjection rats. CeA muscimol/baclofen rats all remained at 0 or 1 daily infusion from days 3-10, whereas control rats rose gradually to $\sim 20$ infusions by day 10 (day $\times$ group interaction: $F_{(7,42)}=$ $2.5, p=0.03$; Fig. $7 B$ ). We note that CeA muscimol/baclofen microinjections may induce some degree of general motor suppression (Mahler and Berridge, 2009), which could have contributed to disrupting cocaine self-administration here. However, clearly, motor suppression was not so great as to by itself disrupt self-administration given that no disruption of self-administration was seen after muscimol/baclofen microinjections on days 1 and 2, but only emerged when head caps were first connected to fiber-optic tethers on day 3. At that point, CeA muscimol/baclofen suppression of motor, sensory, motivational, and/or associative functions apparently only then became sufficient to disrupt the more challenging task demands presented by having to make nose pokes while head tethered in to self-administer cocaine.

The relatively severe disruption of cocaine self-administration by CeA muscimol/baclofen microinjections (when combined with head cables) versus the much milder effects of CeA halorhodopsin illumination might reflect less neuronal inhibition by halorhodopsin than by muscimol/baclofen microinjections. This would be consistent with Fos plume data, because halorhodopsin here induced anti-plumes in which the zone of suppression to $50 \%$ of normal Fos levels extended $\sim 0.25 \mathrm{~mm}$ in radius from fiber-optic tip. By comparison, CeA muscimol microinjections have produced larger anti-plumes in which the zone of 50\% Fos suppression extended $0.75 \mathrm{~mm}$ from microinjector tip (Mahler and Berridge, 2009). A 3-fold difference in radius would correspond to a $>25$-fold difference in volumes of CeA tissue inhibited by halorhodopsin illumination versus muscimol microinjection $\left(0.06-1.76 \mathrm{~mm}^{3}\right.$; assuming approximately spherical shapes). Also supporting the possibility that halorhodopsin causes only mild neurobiological inhibitions, electrophysiological studies have reported that, in infralimbic cortex, $70 \%$ of affected neurons were inhibited, but $30 \%$ of neurons were oppositely excited, by halorhodopsin (Smith et al., 2012). Similarly, in ventral pallidum, $80 \%$ of neurons were unaffected by halorhodopsin, whereas in the affected $20 \%$ subgroup, two of three neurons were inhibited and the remaining one neuron was excited (Chang et al., 2017). If comparably weak electrophysiological effects occurred in CeA, then this might also help to explain why the behavioral effects of CeA halorhodopsin were relatively weak. 
A

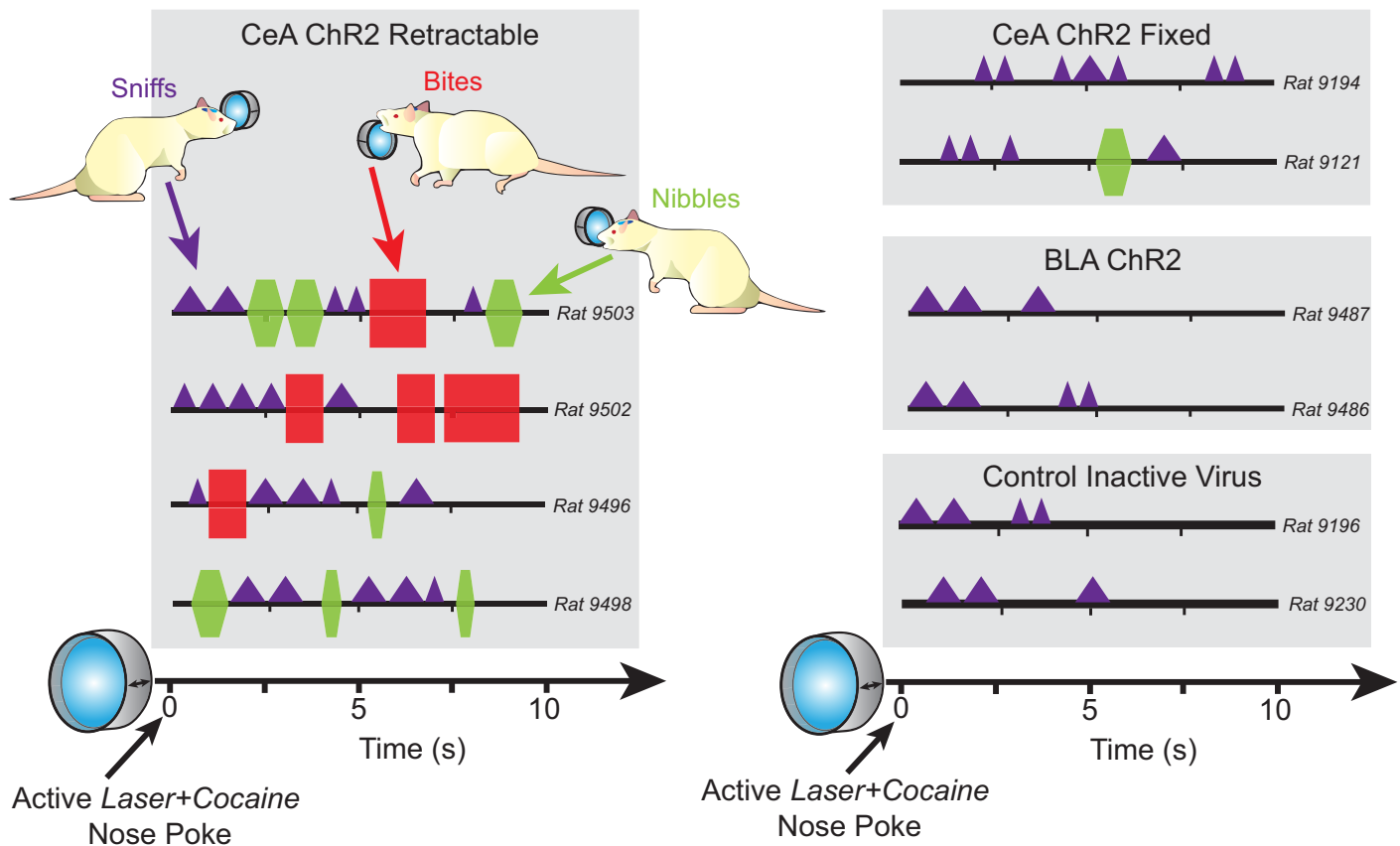

B

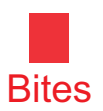

C

Nibbles
D

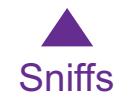

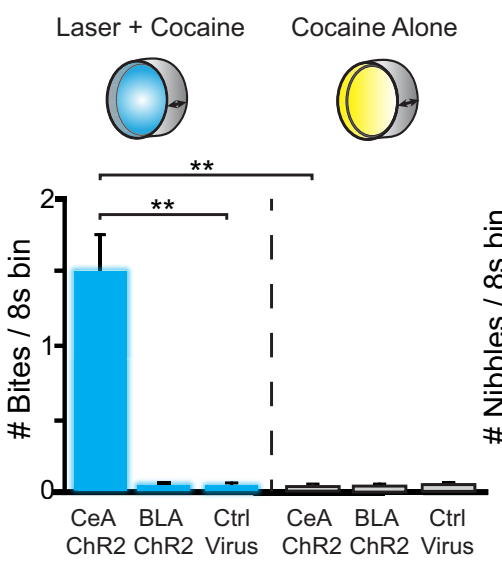
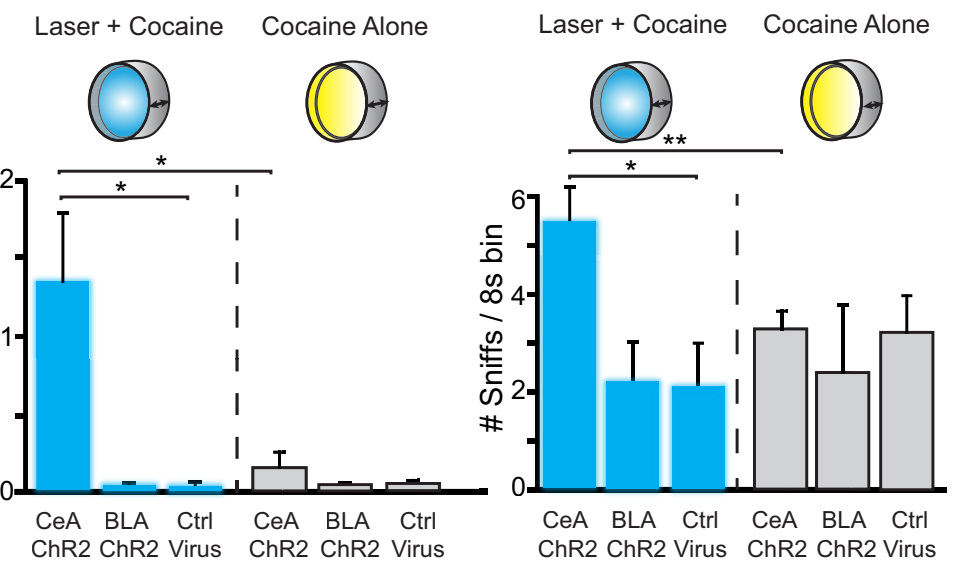

Figure 6. Consummatory bites, nibbles, and sniffs at porthole. $A$, Topography of behavior toward the laser + cocaine porthole among representative rats from each group (CeA ChR2 rats toward a retractable or fixed port, BLA ChR2, and control inactive virus rats). Each choreograph shows a "typical" response $\sim 30$ min into a session at a porthole during the $8 \mathrm{~s}$ after a successful nose poke that earns a cocaine infusion and laser illumination plus accompanying auditory cue. Bites (red squares) and nibbles (green hexagons) predominantly occurred only in CeA ChR2 rats toward their laser + cocaine retractable port, whereas sniffs (purple triangles) were more common toward fixed ports and in other groups. (eA ChR2 rats on average bit $(\boldsymbol{B})$, nibbled $(\boldsymbol{C})$, and sniffed $(\boldsymbol{D})$ at greater numbers during each $8 \mathrm{~s}$ bin after successful nose poke of their laser + cocaine retractable porthole (blue bars) compared with both their cocaine alone port (gray bars) or compared with BLA ChR2 and Control inactive virus rats at their laser + cocaine retractable port (blue bars). Data are shown as mean \pm SEM. ${ }^{*} p<0.05{ }^{* *} p<0.01$.

\section{CeA muscimol/baclofen inhibition prevents CeA ChR2 control of motivation}

In a final CeA inhibition group, we tested whether muscimol/ baclofen CeA inhibition during training would block the ability of simultaneous CeA ChR2 excitation to intensify cocaine motivation and establish preference for the laser + cocaine option. CeA inhibition/excitation rats received muscimol/baclofen microinjections before sessions on each of the first $4 \mathrm{~d}$ of training. In each session, they received CeA ChR2 laser pairings with one cocaine option, as in the CeA ChR2 groups above. Results showed that CeA muscimol/baclofen microinjections completely prevented CeA ChR2 laser pairing from generating any detectable enhancement in motivation for cocaine or establishing any detectable preference for the laser + cocaine option over the cocaine-alone option $\left(F_{(1,3)}=1.0, p=0.39\right.$; Fig. $\left.7 C\right)$. Instead, these rats made only $0-1$ nose pokes per session, randomly distributed between the 2 options. On the fifth and sixth day, muscimol/baclofen microinjections were omitted to assess whether the suppression of self-administration was enduring or instead was CeA state dependent. Without simultaneous CeA inhibition, cocaine intake immediately jumped on the fifth day to $\sim 30$ total infusions and a 3:1 preference immediately emerged so that CeA ChR2 rats now made $\sim 25$ nose pokes for their laser + cocaine option versus $\sim 6$ nose pokes for cocaine alone $\left(t_{(3)}=3.7, p=0.03\right.$, 
A

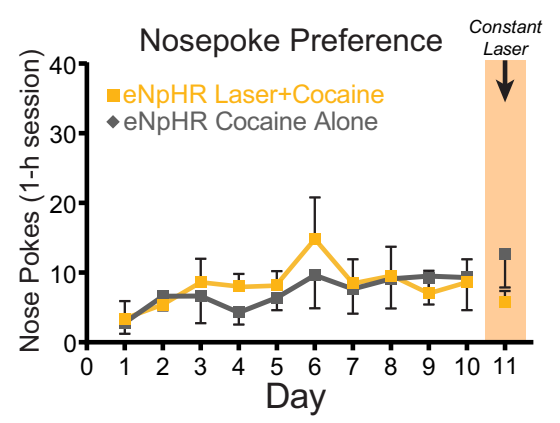

Halorhodopsin CeA Inactivation

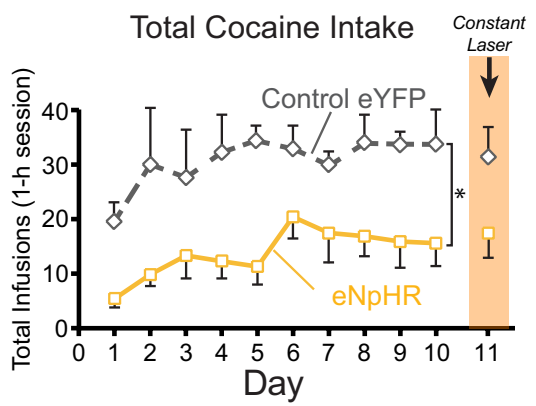

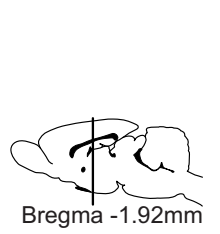

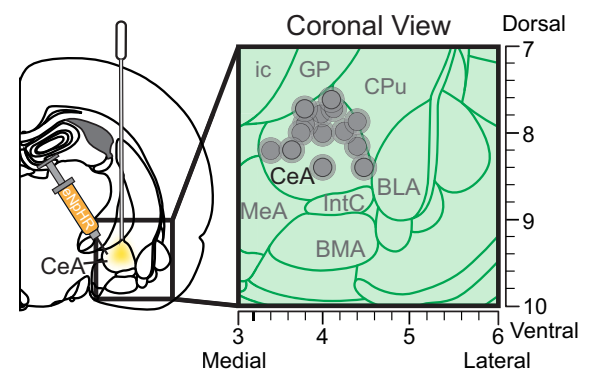

B
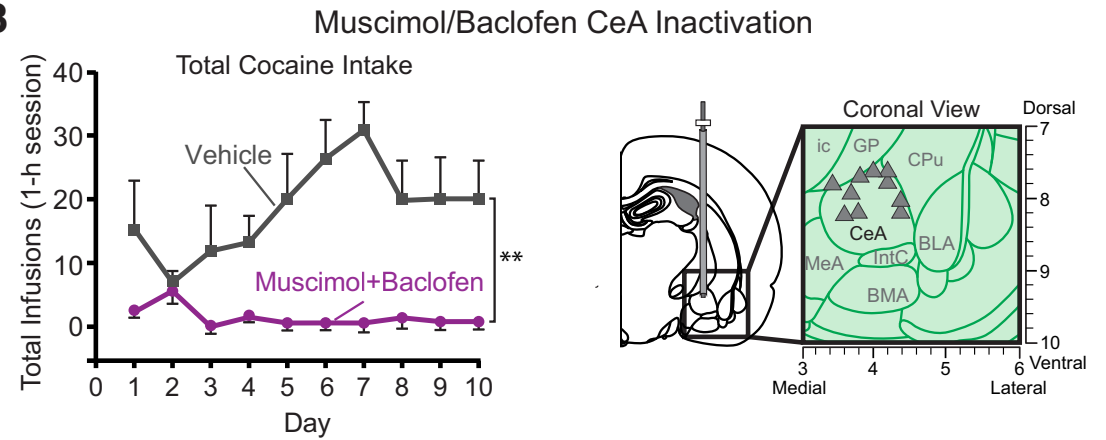

C

CeA muscimol/baclofen prevents Laser+Cocaine preference
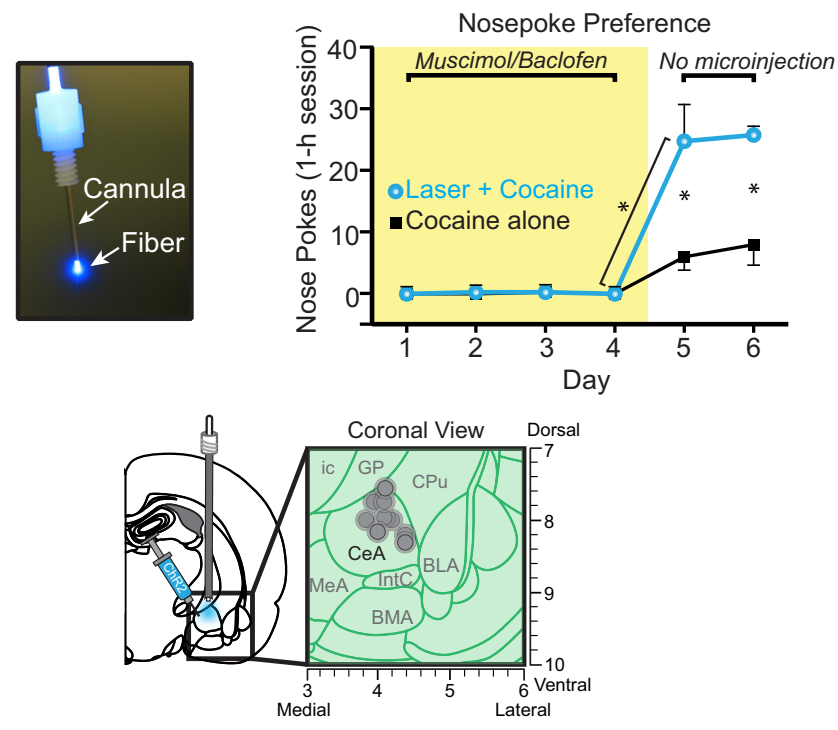

Figure 7. Loss of CeA function. Optogenetic CeA inhibition does not alter choice, but pharmacological CeA inhibition abolishes cocaine pursuit and laser preference. A, Optogenetic CeA inhibition paired with earning one cocaine reward failed to alter nose poke preference, as CeA halorhodopsin rats $(\mathrm{eNpHR}, n=7)$ chose equally between the laser + cocaine (solid orange lines with orange filled squares) and cocaine alone (solid gray line with gray filled squares). However, over the course of the $10 \mathrm{~d}$, total cocaine intake graph on right shows that halorhodopsin rats (eNpHR; solid orange lines with open squares outlined in orange) selfadministered less cocaine infusions compared with control inactive virus rats (control eYFP; $n=2$; dashed gray lines with open

$95 \% \mathrm{CI}=2.4$ to $35 ; d=2.19)$. This level of effort was $\sim 20$ times higher than on the previous day 4 , when muscimol/baclofen microinjections had been received $\left(t_{(3)}=\right.$ $4.14, p=0.03,95 \% \mathrm{CI}=-43$ to $-5 ; d=$ -3.7 ), even though responses at the cocaine alone port did not rise significantly from days $4-5\left(t_{(3)}=2.3, p=0.11,95 \%\right.$ $\mathrm{CI}=-19$ to 3.3 . This renewed selfadministration pattern remained stable on day 6 , when muscimol/baclofen microinjections again were omitted and CeA ChR2 preference for laser + cocaine continued at $\sim 26$ entries in the laser + cocaine port versus 8 in the cocaine alone port $\left(t_{(3)}=4.9, p=0.02,95 \% \mathrm{CI}=6\right.$ to $29 ; d=2.8)$.

\section{Progressive ratio: $\mathrm{CeA}$ ChR2 stimulation amplifies incentive motivation breakpoint}

Does CeA ChR2 stimulation actually increase the intensity of incentive motivation for cocaine? We ran a progressive ratio or breakpoint test to assess independently whether laser would increase effort rats were willing to exert to obtain cocaine in a $2 \mathrm{~d}$ within-subject comparison. Rats were presented with only one cocaine option per day (order counterbalanced across rats): either cocaine alone or laser + cocaine. On each day, the available porthole earned their customary outcome, either cocaine infusions plus $8 \mathrm{~s}$ laser illuminations and its auditory cue (laser + cocaine) or only cocaine infusions plus its distinctive auditory cue (cocaine alone). However, the effort required to earn each reward increased progressively after each infusion during a session. Overall, CeA ChR2 rats were willing to work $\sim 8$ times harder on their laser + cocaine day (breakpoint $=75$ ) than on their cocaine alone day (breakpoint $=9 ; n=11$; Wilcoxon signedranks test, $Z=-2.93, p=0.003, r=0.88$;

$\leftarrow$

diamonds outlined in gray). $\boldsymbol{B}$, Muscimol/baclofen CeA inactivation. Rats receiving microinjections into CeA of muscimol/ baclofen (muscimol + baclofen; $n=5$; solid purple lines with filled purple circles) self-administered fewer infusions than rats receiving vehicle (vehicle; $n=4$; solid gray lines with filled gray circles). C, CeA muscimol/baclofen prevents laser + cocaine preference. When CeA microinjections of muscimol/ baclofen were administered for the first $4 \mathrm{~d}$ of training, cocaine responding was completely suppressed for both cocaine options in the 2-choice task. As soon as microinjections ceased (starting on days $5-6)$, CeA ChR2 rats $(n=4)$ exclusively chose the laser + cocaine option (solid blue lines with blue filled circles) over and above their cocaine alone option (solid black lines with black filled squares), as well as above the prior day when receiving muscimol/baclofen. Data are shown as mean \pm SEM. ${ }^{*} p<0.05^{* *} p<0.01$. 
A

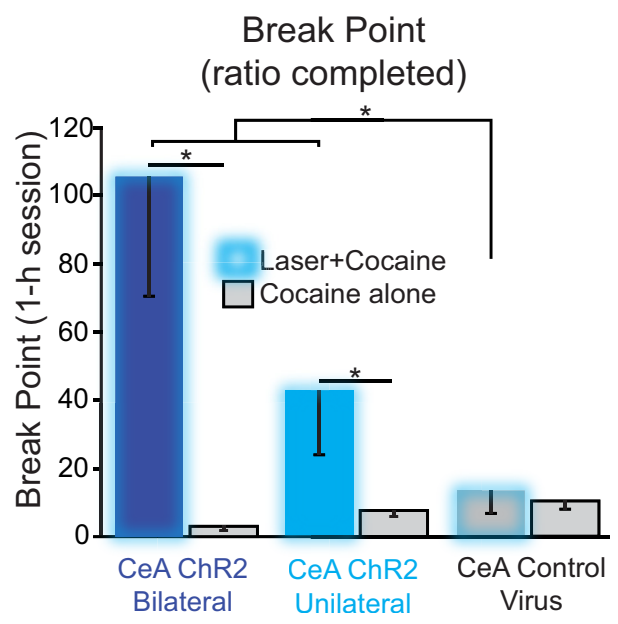

B

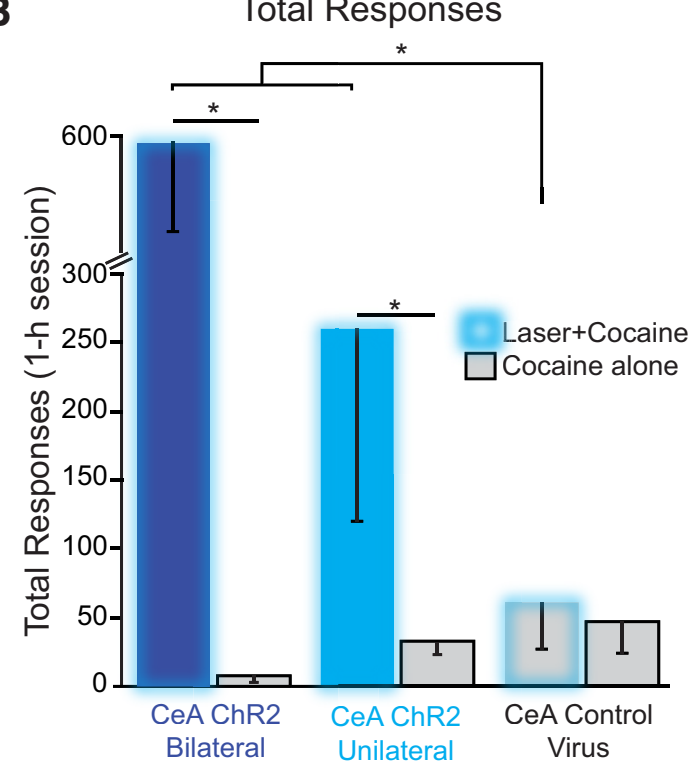

C

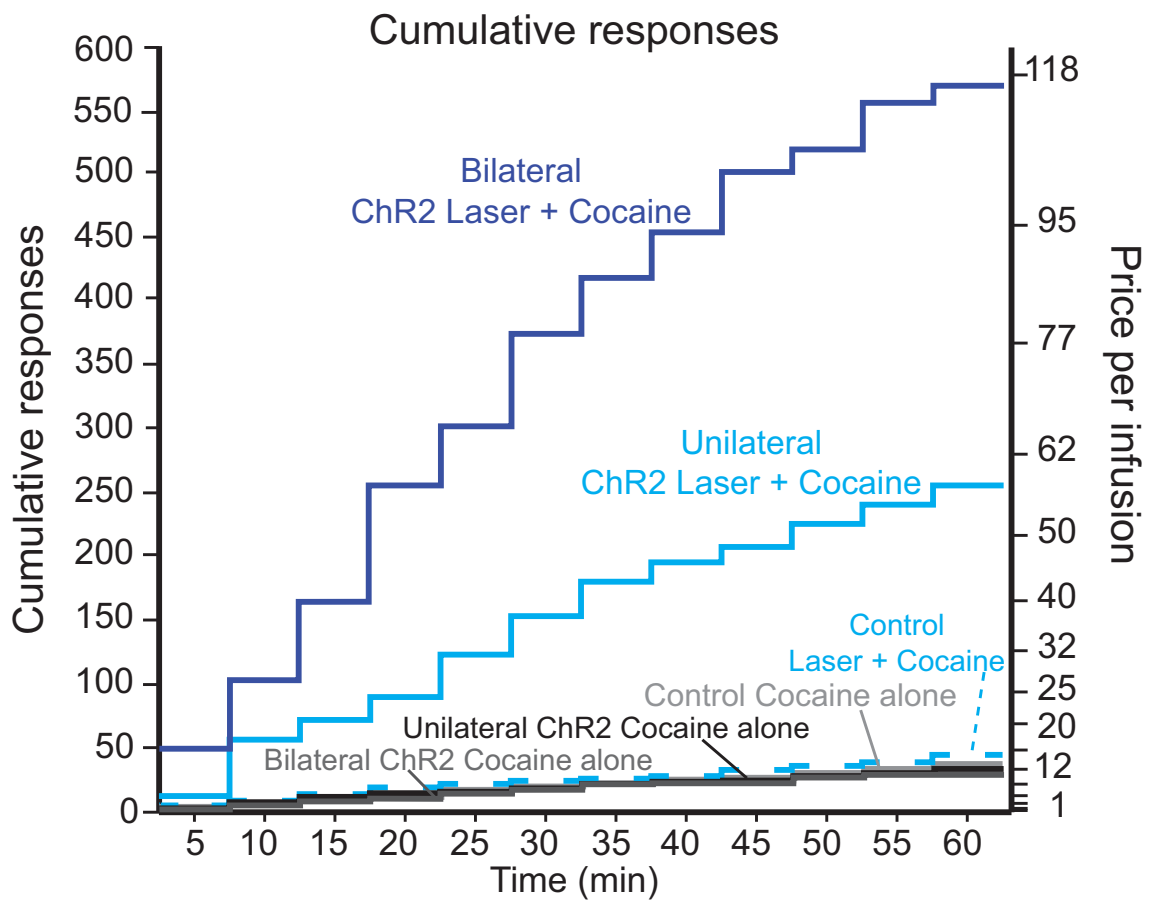

Figure 8. CeA ChR2 stimulation amplifies breakpoint motivation. A progressive ratio test of breakpoint was given on 2 consecutive days (counterbalanced order). On one day, rats earned laser + cocaine accompanied by its $8 \mathrm{~s}$ auditory cue. On the other day, rats earned cocaine alone plus its own $8 \mathrm{~s}$ auditory cue. On each day, effort required to obtain the next cocaine infusion increased exponentially after each earned infusion. $A$, CeA ChR2 rats reached higher breakpoints (maximum effort price rats were willing to pay) for laser + cocaine than for cocaine alone: making more nose pokes overall $(\boldsymbol{B})$ and (C). Bilateral amygdala laser illumination increased motivation more than unilateral laser illumination in CeA ChR2 rats (CeA ChR2 bilateral; dark blue bars; $n=3 ;$ CeA ChR2 unilateral; light blue bars; $n=8$ ). In contrast, control virus rats worked equally hard for cocaine regardless of laser condition and at much lower levels than CeA ChR2 rats did for laser + cocaine (CeA control virus; gray bars; $n=5$ ). Data are shown as mean \pm SEM. ${ }^{*} p<0.05$.

Fig. 8A). Further, among CeA ChR2 laser + cocaine sessions, rats with bilateral CeA illumination had breakpoints nearly twice those of rats receiving unilateral illumination ( 130 vs $54 ; n=3$ bilateral, $n=9$ unilateral), although with only 3 bilateral rats, this difference was not statistically significant $\left(\chi^{2}=-5.29, p=0.24\right)$. Overall, the total cumulative number of pokes per day rose under laser + cocaine day by an order of magnitude to $348 \pm 140$ from $25 \pm 10$ on cocaine alone day $(Z=-2.93 p=0.003, r=0.88$; Fig. $8 B)$ for the same rats. This difference was evident within the first 5 min of each day's session (23 laser + cocaine vs 3 cocaine alone pokes; $Z=-2.37, p=$
$0.018, r=0.71)$ and continued robustly for the remainder of the 60 min session $(Z=-2.93, p=0.003, r=0.88$; Fig. $8 C)$. In contrast, breakpoints of control inactive virus rats were insensitive to the presence of CeA laser (breakpoint $=21$ and 16; $n=4 ; Z=-0.37, p=$ $0.715)$. Inactive virus control rats also made similar total numbers of nose pokes on both days (laser + cocaine $=60$; cocaine alone $=48$; $Z=-0.405, p=0.686)$ and fewer overall than CeA ChR2 rats (Mann-Whitney $U$ test, $Z=-2.03, p=0.04, r=0.61$ ). The order of laser + cocaine versus days did not influence responding (MannWhitney $U$ test, $Z=-1.14, p=0.26$ ). 
A Laser Spout Control Spout
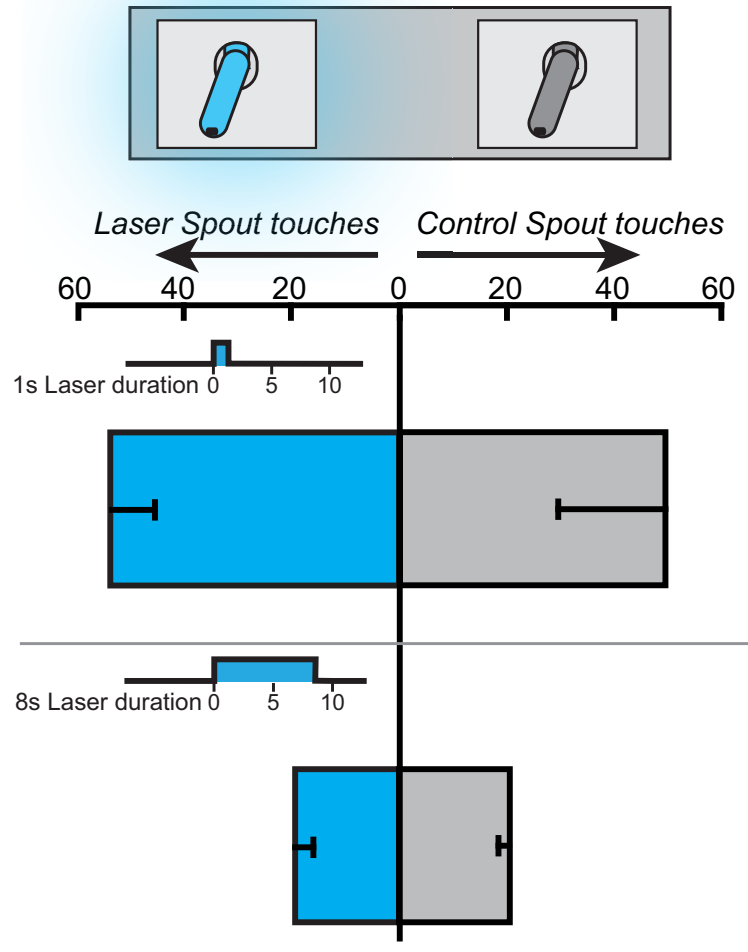

B
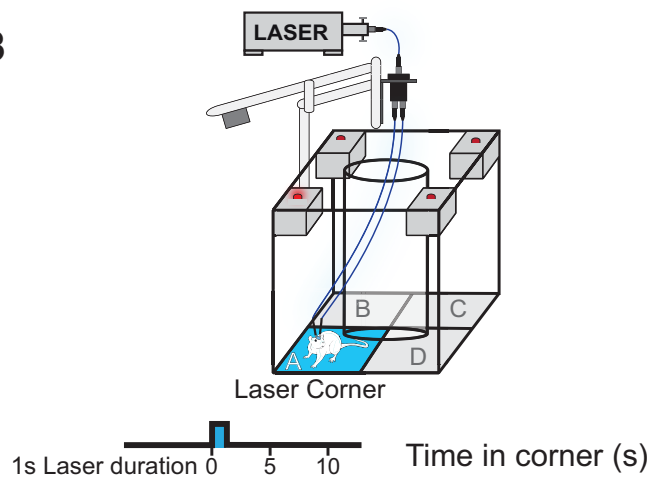

$\%$ Time in corner
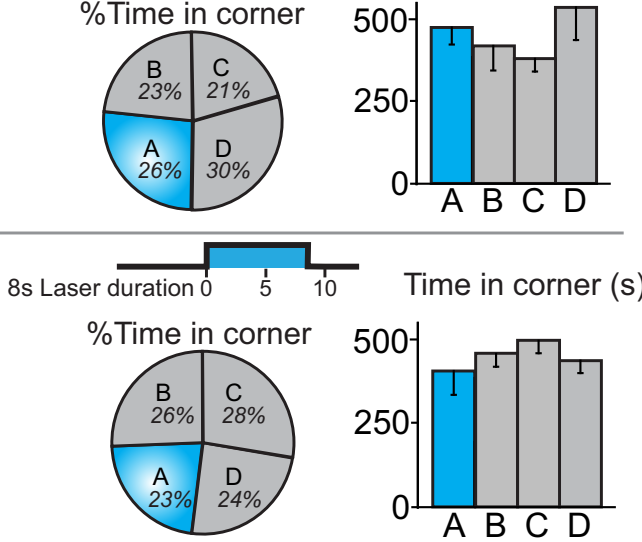

Figure 9. CeA ChR2 laser fails to support self-stimulation. $A$, In an active spout-touch self-stimulation test, rats failed to touch the spout delivering CeA ChR2 stimulation ( $25 \mathrm{~Hz}, 8-10 \mathrm{~mW}, 1$ and $8 \mathrm{~s}$ durations, $n=6$ and $n=3$, respectively) any more than the other control spout that delivered nothing. $\boldsymbol{B}$, In a passive location-based self-stimulation test, rats neither preferred nor avoided the corner location where CeA ChR2 stimulation was delivered compared with other three corners that lacked laser. In other words, rats simply ignored the laser location (blue laser, $25 \mathrm{~Hz}, 8-10 \mathrm{~mW}$, 1 and 8 s durations) ( $n=4$ and $n=3$, respectively). Data are shown as mean \pm SEM.

\section{CeA ChR2 laser by itself fails to support self-stimulation in same rats}

In three separate tests of laser self-stimulation, CeA ChR2 illumination by itself failed to reinforce responses even though laser had previously potentiated cocaine pursuit in the same rats: an active response task (object-touch self-administration), a passive response task (place-based real-time self-stimulation), and an instrumental nose-poke response task (minus cocaine delivery).

In a spout-touch self-stimulation task requiring active responses, every touch on a designated metal spout (empty drinking spout) with paw or mouth closed an electrical contact and earned a brief pulse of laser stimulation (either 1 or $8 \mathrm{~s}$ duration for different rats; $25 \mathrm{~Hz}, 8-10 \mathrm{~mW}$, blue laser) (Kravitz et al., 2012), whereas touching an alternative spout earned nothing. Results showed that CeA ChR2 rats failed to touch the active spout any more than the inactive spout $\left(n=12 ; F_{(1,10)}=0.013\right.$, $p=0.91$; Fig. $9 A$ ). No detectable self-stimulation behavior was obtained at either $1 \mathrm{~s}$ pulse duration $\left(n=6 ; F_{(1,5)}=0.046, p=\right.$ $0.84)$ or 8 s pulse durations $\left(n=6 ; F_{(1,5)}=0.075, p=0.79\right)$. Rats touched both spouts between 20 and 70 times per session for each of 3 consecutive sessions (possibly attracted because spouts resembled water drinking spouts in home cage), but with approximately equal frequency $\left(F_{(2,20)}=0.72, p=0.5\right)$. On the first $2 \mathrm{~d}$, rats touched both spouts less frequently if earning $8 \mathrm{~s}$ duration CeA pulses than $1 \mathrm{~s}$ pulses, possibly suggesting a slight general deterrent effect of longer CeA pulses or general arousing effect of shorter pulses (first day 65 touches $1 \mathrm{~s}$ vs 12 touches $8 \mathrm{~s} ; t_{(2)}=3.2$, $p=0.01,95 \% \mathrm{CI}=16.1$ to $89.5 ; d=2.35$; second day $t_{(10)}=2.5$, $p=0.03,95 \% \mathrm{CI}=-17.9$ to $36.9 ; d=0.45)$. However, even that difference disappeared by the third day $\left(t_{(10)}=0.87, p=0.4\right)$.

In a second active-response task, spout touching was replaced by nose poking as the instrumental response, similar to the instrumental response used for cocaine self-administration. This was to test the alternative interpretation that nose pokes were simply an easier response for rats to acquire and that a difference in task ease explained why CeA laser controlled cocaine selfadministration, but not laser self-stimulation in the spout task. Drug-naive CeA ChR2 rats that had never earned cocaine encountered two portholes (both were retractable or both were fixed for different rats). Nose pokes into one arbitrarily designated porthole earned either $1 \mathrm{~s}$ bins (typical duration for selfstimulation studies) or $8 \mathrm{~s}$ bins (similar to cocaine 2-choice bins) (balanced across different rats) of CeA blue laser illumination (25 $\mathrm{Hz}, 8 \mathrm{~mW}$ ), whereas a second porthole delivered nothing and was counted simply as a control for general activity. Results showed that CeA ChR2 rats failed to nose poke into their laser-delivering porthole any more frequently than into the inactive porthole in both $1 \mathrm{~s}$ laser bins $\left(n=6 ; t_{(5)}=1.23, p=0.273,95 \% \mathrm{CI}=-21.6\right.$ to 16.1$)$ and 8 s laser bins $\left(n=6 ; t_{(5)}=1.34, p=0.24,95 \% \mathrm{CI}=\right.$ -11 to 34$)$. Overall, nose pokes also did not differ between 1 and $8 \mathrm{~s}$ laser bins $\left(F_{(1,5)}=1.18, p=0.33\right)$, nor was there any interaction between porthole preference and bin duration $\left(F_{(1,5)}=1.1\right.$, $p=0.35$ ). Therefore, cocaine-naive CeA ChR2 rats failed to nose poke to self-stimulate CeA laser, indicating that CeA excitation by itself is not sufficient to serve as an independent reinforcer in our two-porthole nose-poke task. 


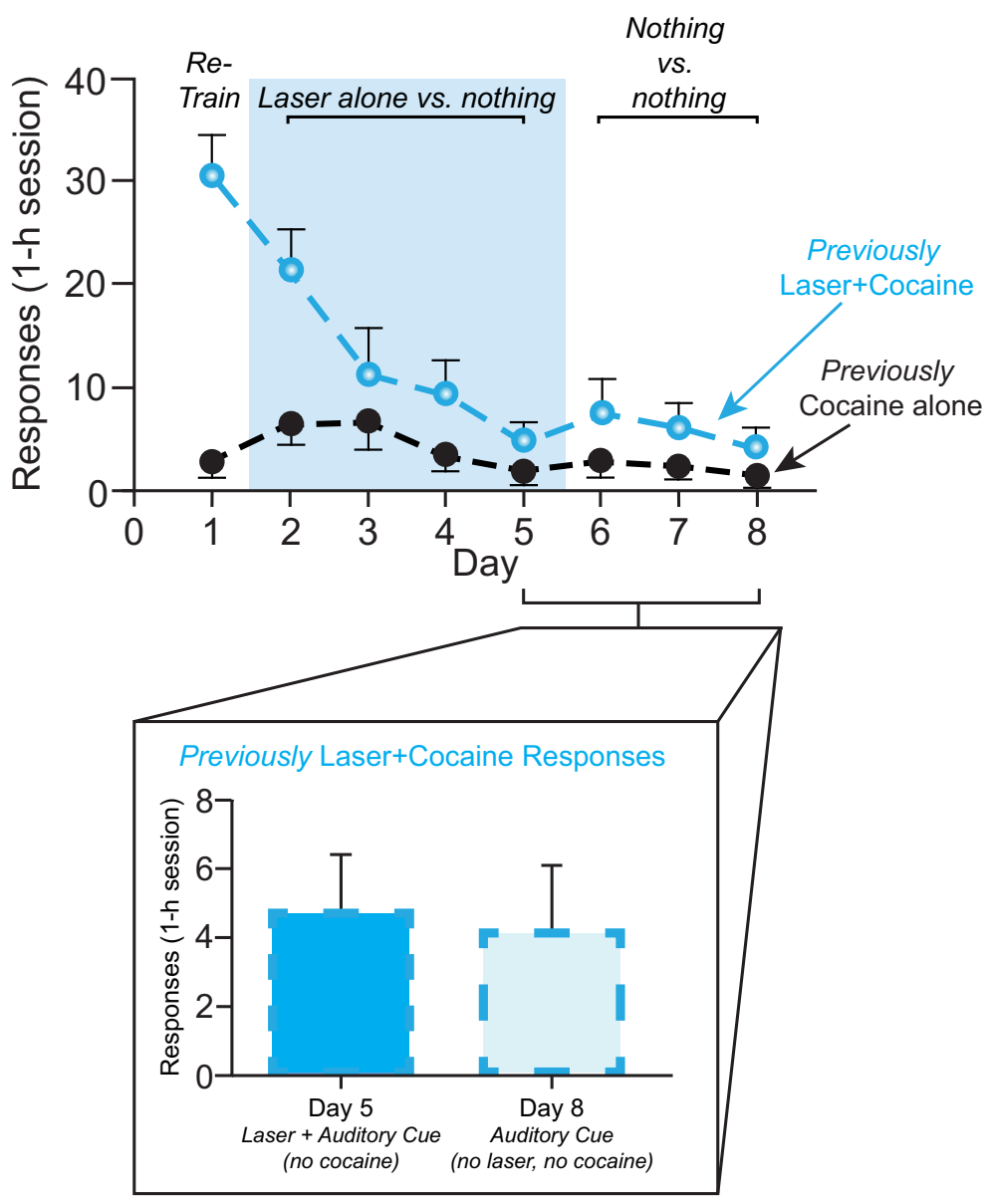

Figure 10. CeA ChR2 laser alone does not maintain nose-poking. Rats were retrained on the two-choice task to choose between laser + cocaine versus cocaine alone. Starting on day 2, cocaine was removed, but rats could still earn laser stimulation by poking into their previous laser + cocaine port (previously laser + cocaine; dashed blue line with blue filled circles). Pokes into their previous cocaine alone port earned nothing (previously cocaine alone; dashed black lines with black filled circles). When laser stimulation was offered alone, responding declined and rats no longer preferred the laser-delivering port. On subsequent days $6-8$, laser was removed and no further decline in responding was observed. A comparison of responding on the last day of laser alone (day 5) and after $3 \mathrm{~d}$ of responding for neither laser nor cocaine (nothing; day 8) showed no difference (inset). Data are shown as mean \pm SEM.

In the passive response or location-based task, in which CeA ChR2 stimulation could be earned even more easily by entering or just remaining in a particular corner while making small movements (Olds and Milner, 1954), CeA ChR2 rats failed to show any self-stimulation or preference for their laser-delivering corner over the other 3 corners $\left(n=7 ; F_{(3,9)}=0.19, p=0.901\right.$; Fig. $9 B)$. Equally, CeA ChR2 rats did not avoid their laser corner regardless of whether laser illumination was earned in $1 \mathrm{~s}$ duration pulses $\left(n=4 ; F_{(3,9)}=2.3, p=0.145\right)$ or in 8 s duration pulses $\left(n=3 ; F_{(3,6)}=0.079, p=0.97\right)$. Instead, rats appeared oblivious to the location of CeA ChR2 stimulation delivered by itself, instead simply exploring the chamber at random. Lack of self-stimulation suggests that CeA ChR2 laser does not add a prediction error or reinforcement signal able to "stamp in" a preceding action.

\section{CeA ChR2 laser fails to maintain responding after cocaine is discontinued}

In a final test of whether CeA ChR2 laser illumination by itself can be sufficient at least to maintain instrumental nose-poke responding (if not to establish nose pokes), we examined the effect of turning off cocaine infusions in CeA ChR2 rats that had already acquired nose-poke responding for the combination of laser + cocaine. In other words, could CeA ChR2 laser by itself at least maintain nose pokes in rats that were already responding at a high level for cocaine accompanied by CeA laser? After $2 \mathrm{~d}$ of refresher training on the original 2-choice task for laser + cocaine and cocaine alone (FR1 schedule), cocaine was suddenly discontinued for the next $4 \mathrm{~d}$ but the laser could still be earned by itself $(n=7)$. That is, the customary porthole still delivered laser as before and both portholes delivered their associated auditory cues, but neither delivered cocaine (laser alone vs nothing). Finally, after $4 \mathrm{~d}$ of laser alone, the laser was also discontinued for the next $3 \mathrm{~d}$ to examine whether its removal dropped responding further (nothing vs nothing; $n=7$ rats). Results showed that, by the second day of laser alone, CeA ChR2 rats lost their preference for the former laser + cocaine option that now delivered laser alone and chose equally at low levels between that and nothing $\left(t_{(6)}\right.$ $=1.01 ; p=0.35,95 \% \mathrm{CI}=-6.6$ to 15.7 ; Fig. 10). CeA ChR2 rats failed to selfstimulate on their laser alone porthole, even though they had previously responded vigorously when it also earned cocaine $\left(F_{(4,24)}=10.22, p=0.000\right)$. Both unilateral laser and bilateral laser rats showed similar declines when only laser by itself was available $(n=3$ unilateral and $n=4$ bilateral; $F_{(1,5)}=0.012, p=$ 0.92). Finally, when CeA laser was additionally discontinued several days later, there was no further drop from laser alone to nothing ( $5 \pm 2$ vs $4 \pm 2$ responses on days 5 and 8 , respectively; $t_{(6)}=0.36 ; p=$ $0.73,95 \% \mathrm{CI}=-3.3$ to 4.4 ). Therefore, without cocaine, CeA ChR2 laser failed to maintain any detectable preference or instrumental responding above complete extinction levels. Instead, CeA laser appeared entirely worthless to the same rats in which it had established intense and narrowly focused motivation for cocaine.

\section{Discussion}

Our results demonstrate that pairing CeA ChR2 stimulation with a particular option to earn intravenous cocaine narrowly focused amplified motivation solely to its paired cocaine option at the expense of nearly ignoring the alternative cocaine option and intensified the level of incentive motivation to obtain cocaine, resulting in greater cocaine consumption. In independent progressive ratio tests of intensity of incentive motivation, CeA ChR2 stimulation further amplified the breakpoint effort price that rats were willing to pay for cocaine by more than eight times. This pattern closely resembles the CeA ChR2 amplification and narrowing of sucrose motivation that we reported previously (Robinson et al., 2014). Conversely, CeA inhibition by optogenetic halorhodopsin here mildly impaired cocaine consumption and stronger GABAergic inhibition by muscimol/baclofen microinjections nearly abolished self-administration by tethered rats and prevented CeA ChR2 enhancement or focusing of moti- 
vation. These results indicate that CeA-related circuitry can powerfully control the amplitude and targeting of motivation for cocaine.

CeA ChR2 pairing also generated intense consummatory bite and nibble reactions directed specifically toward the metal laser + cocaine porthole, in addition to increasing consummatory sniffing of that laser-associated cocaine cue (a more typical conditioned response to cocaine cues). Bites and nibbles are common rat consummatory behaviors elicited by cues for sucrose or food rewards, but to our knowledge have not been reported for cocaine cues. Here, bites and nibbles were never emitted by control rats earning cocaine nor by BLA ChR 2 rats or even by CeA ChR2 rats toward their cocaine alone porthole. Consummatory bites emerged only when several conditions were met simultaneously: (1) CeA ChR2 laser was paired with the target cocaine porthole; (2) the metal porthole actively moved, appearing abruptly into the chamber and retracting back out after cocaine was earned; and (3) cocaine was actually earned by that option. Further, a fourth condition of cocaine intoxication dramatically facilitated oral consummatory behaviors: bites, nibbles, and sniffs all became most intense near the end of a session, when CeA ChR2 rats had already consumed a substantial dose of cocaine. Consummatory responses are a signature feature of incentive salience when attributed toward a Pavlovian reward cue to the extent that individuals sometimes try to consume a 'wanted' cue as though it were the reward (Mahler and Berridge, 2009). Here, we hypothesize that CeA ChR2 pairing with cocaine amplified the incentive salience of its associated cue, adding a new motivation status that made it more attractively biteable.

\section{Amplified cocaine value, not transferred laser value}

Despite powerfully intensifying and narrowing motivation to take cocaine and making its cue more attractive, CeA ChR2 stimulation apparently lacked any reinforcement value on its own without cocaine. Even the same rats that had pursued only their laser + cocaine option completely failed to show laser preferences when given opportunities to earn self-stimulation with CeA $\mathrm{ChR} 2$ laser alone. CeA ChR2 rats neither touched a spout nor made nose pokes in a porthole to earn laser and did not even remain or return to a location where laser was delivered. Further, CeA ChR2 laser by itself also failed to maintain instrumental nose-poke responding that had been previously established intensely by pairing that laser with cocaine. Therefore, by itself, CeA ChR2 laser appeared worthless to these rats. Although CeA ChR2 self-stimulation might be found in future using different situations, it seems clear that CeA ChR2 laser was not a potent reinforcer with our parameters.

Lack of independent reinforcement by laser rules out the possibility that CeA ChR2 stimulation acted as a prediction error teaching signal to create a learned expectation of greater reward, that the laser acted to strengthen stimulus-response habit associations, or that laser was ever sought by our rats as an independent hedonic reward. We conclude that CeA ChR2 enhancement of cocaine motivation cannot be explained by mere transfer of any additive laser reinforcement/reward signal to its paired cocaine. Instead, CeA ChR2 enhancement of cocaine motivation was greater than the sum of its two separate parts, namely laser stimulation value and cocaine value, assessed separately. We suggest that CeA ChR2 laser specifically transforms the motivational value of earning its paired sensory reward and enhances incentive salience of its cocaine cue. This CeA ChR2 value transformation seems unable to act in vacuo on any relatively neutral stimulus (spout, porthole, location), but rather requires some motivation- ally salient sensation on which to act, such as a cocaine reward or sucrose reward.

\section{Localization of function in CeA for enhanced motivation}

Effective sites for amplifying motivation for paired cocaine were nearly all clustered within CeA or slightly above, so downwardprojecting light would penetrate CeA. In contrast, nearly all BLA ChR2 sites were ineffective.

Laser-induced Fos plumes were much smaller $(0.1-0.3 \mathrm{~mm}$ radius) than GFP virus infection zones ( $\sim 1 \mathrm{~mm}$ radius). That difference suggests ChR2-infected CeA neurons may need to be within $0.3 \mathrm{~mm}$ of an $8-10 \mathrm{~mW}$ optic fiber tip to receive sufficient light to alter neuronal function, induce Fos translation, and presumably increase firing. Based on this assumption to aid localization of function, effective sites were evenly spread in most CeA subdivisions, including both the $\mathrm{CeM}$ and $\mathrm{CeL}$, as well as the CeC. It has been suggested that $\mathrm{CeL}$ mediates appetitive motivation for reward (Cai et al., 2014) and reduces anxiety (Tye et al., 2011), whereas CeM mediates fearful or defensive behaviors (Haubensak et al., 2010; Namburi et al., 2015). However, our results imply that neurons in CeM and CeL likely contributed to CeA ChR2 enhancement of cocaine motivation here. As a caveat, though, we acknowledge that many of our CeM Fos plumes may also have partly penetrated into CeL, and thus not have been fully contained in CeM. Future work could examine anatomical subdivisions or neuronal subpopulation roles more specifically either by creating smaller Fos plumes or by probing neurochemical subpopulations within CeM and CeL (Wolff et al., 2014; Gafford and Ressler, 2015).

Although BLA has been implicated in both reward-related and fearful behaviors, often by lesion or related loss-of-function studies (Kochli et al., 2015; McGaugh, 2015; Wassum and Izquierdo, 2015), BLA was not effective for ChR2 enhancement of cocaine motivation here. That CeA versus BLA difference replicates the pattern that we reported previously for CeA ChR2 amplification of motivation to earn sucrose, indicating similar anatomical specificity for optogenetic control of a natural sensory reward and a drug reward (Robinson et al., 2014). CeA is also typically more effective than BLA for pharmacological microinjection enhancements of incentive motivation (Corbit and Balleine, 2005; Mahler and Berridge, 2009; DiFeliceantonio and Berridge, 2012; Holland and Hsu, 2014). CeA is also important in incubation of cue-triggered drug craving (Lu et al., 2005; Shaham and Hope, 2005; Lu et al., 2007; Funk et al., 2016). A CeA advantage for generating intense incentive motivation may be related to CeA's macrosystem status as a "striatal-level structure" (e.g., containing mostly GABAergic neurons), similar to several other striatal structures where stimulations also may generate intense motivation for rewards (e.g., nucleus accumbens; some regions of neostriatum). In contrast, BLA has the status of a "cortical-level structure" (e.g., mostly glutamatergic neurons, which project in turn to $\mathrm{CeA}$ ) in the same macrosystem framework (Alheid and Heimer, 1988; Swanson and Petrovich, 1998; Swanson, 2003; Zahm, 2006; Heimer, 2008).

Regarding larger mesocorticolimbic circuitry, CeA is known to modulate mesolimbic dopamine systems in tegmentum and nucleus accumbens activity (Ahn and Phillips, 2002) via outputs to intermediary ventral pallidum, lateral hypothalamus, ventral tegmentum, and other targets (Yoshida et al., 2006; Heimer, 2008; Janak and Tye, 2015; Reppucci and Petrovich, 2016). CeA ChR2 recruitment of VTA, mesolimbic dopamine projections, and related limbic circuitry may well be part of the mechanism that enhanced incentive motivation here. 


\section{Potential roles of CeA circuitry in addiction}

In addiction, intense motivation may become narrowly focused on a particular reward, such as taking drugs, at the expense of neglecting other life rewards. A challenge for addiction neuroscience has been to understand how brain circuitry carries out the narrow focusing of desire combined with amplification of motivation intensity. Our results confirm that optogenetic activation of CeA-related circuitry, paired with one particular reward option, produces narrowly focused yet intense motivation and extends this phenomenon to intravenous cocaine reward. Our results also demonstrate a potentially "irrational" feature of this CeA-generated intense motivation that might be shared with addiction, in that motivation enhancement was far greater than the sum of its constituent reinforcer elements (i.e., cocaine alone plus CeA ChR2 laser alone).

\section{References}

Ahn S, Phillips AG (2002) Modulation by central and basolateral amygdalar nuclei of dopaminergic correlates of feeding to satiety in the rat nucleus accumbens and medial prefrontal cortex. J Neurosci 22:10958-10965. Medline

Alheid GF, Heimer L (1988) New perspectives in basal forebrain organization of special relevance for neuropsychiatric disorders: the striatopallidal, amygdaloid, and corticopetal components of substantia innominata. Neuroscience 27:1-39. CrossRef Medline

Balleine BW, Killcross S (2006) Parallel incentive processing: an integrated view of amygdala function. Trends Neurosci 29:272-279. CrossRef Medline

Cai H, Haubensak W, Anthony TE, Anderson DJ (2014) Central amygdala PKC-delta $(+)$ neurons mediate the influence of multiple anorexigenic signals. Nat Neurosci 17:1240-1248. CrossRef Medline

Chang SE, Smedley EB, Stansfield KJ, Stott JJ, Smith KS (2017) Optogenetic inhibition of ventral pallidum neurons impairs context-driven saltseeking. J Neurosci 37:5670-5680. Medline

Corbit LH, Balleine BW (2005) Double dissociation of basolateral and central amygdala lesions on the general and outcome-specific forms of Pavlovian-instrumental transfer. J Neurosci 25:962-970. CrossRef Medline

Crombag HS, Badiani A, Chan J, Dell'Orco J, Dineen SP, Robinson TE (2001) The ability of environmental context to facilitate psychomotor sensitization to amphetamine can be dissociated from its effect on acute drug responsiveness and on conditioned responding. Neuropsychopharmacology 24:680-690. CrossRef Medline

DiFeliceantonio AG, Berridge KC (2012) Which cue to "want'? Opioid stimulation of central amygdala makes goal-trackers show stronger goaltracking, just as sign-trackers show stronger sign-tracking. Behav Brain Res 230:399-408. CrossRef Medline

Faure A, Reynolds SM, Richard JM, Berridge KC (2008) Mesolimbic dopamine in desire and dread: enabling motivation to be generated by localized glutamate disruptions in nucleus accumbens. J Neurosci 28: 7184-7192. CrossRef Medline

Funk D, Coen K, Tamadon S, Hope BT, Shaham Y, Lê AD (2016) Role of central amygdala neuronal ensembles in incubation of nicotine craving. J Neurosci 36:8612-8623. CrossRef Medline

Gafford GM, Ressler KJ (2015) GABA and NMDA receptors in CRF neurons have opposing effects in fear acquisition and anxiety in central amygdala vs bed nucleus of the stria terminalis. Horm Behav 76:136-142. Medline

Haubensak W, Kunwar PS, Cai H, Ciocchi S, Wall NR, Ponnusamy R, Biag J, Dong HW, Deisseroth K, Callaway EM, Fanselow MS, Lüthi A, Anderson DJ (2010) Genetic dissection of an amygdala microcircuit that gates conditioned fear. Nature 468:270-276. CrossRef Medline

Heimer L 2008 Anatomy of neuropsychiatry: the new anatomy of the basal forebrain and its implications for neuropsychiatric illness. Boston: Academic/Elsevier.

Ho CY, Berridge KC (2014) Excessive disgust caused by brain lesions or temporary inactivations: mapping hotspots of the nucleus accumbens and ventral pallidum. Eur J Neurosci 40:3556-3572. CrossRef Medline

Holland PC, Hsu M (2014) Role of amygdala central nucleus in the potentiation of consuming and instrumental lever-pressing for sucrose by cues for the presentation or interruption of sucrose delivery in rats. Behav Neurosci 128:71-82. CrossRef Medline

Janak PH, Tye KM (2015) From circuits to behaviour in the amygdala. Nature 517:284-292. CrossRef Medline

Kearns DN, Weiss SJ (2004) Sign-tracking (autoshaping) in rats: a comparison of cocaine and food as unconditioned stimuli. Learn Behav 32:463476. CrossRef Medline

Kochli DE, Thompson EC, Fricke EA, Postle AF, Quinn JJ (2015) The amygdala is critical for trace, delay, and contextual fear conditioning. Learn Mem 22:92-100. CrossRef Medline

Kravitz AV, Kreitzer AC (2011) Optogenetic manipulation of neural circuitry in vivo. Curr Opin Neurobiol 21:433-439. CrossRef Medline

Kravitz AV, Tye LD, Kreitzer AC (2012) Distinct roles for direct and indirect pathway striatal neurons in reinforcement. Nat Neurosci 15:816-818. CrossRef Medline

LeDoux JE (2000) Emotion circuits in the brain. Annu Rev Neurosci 23: 155-184. CrossRef Medline

Li X, Zeric T, Kambhampati S, Bossert JM, Shaham Y (2015) The central amygdala nucleus is critical for incubation of methamphetamine craving. Neuropsychopharmacology 40:1297-1306. CrossRef Medline

Lu L, Hope BT, Dempsey J, Liu SY, Bossert JM, Shaham Y (2005) Central amygdala ERK signaling pathway is critical to incubation of cocaine craving. Nat Neurosci 8:212-219. CrossRef Medline

Lu L, Uejima JL, Gray SM, Bossert JM, Shaham Y (2007) Systemic and central amygdala injections of the mGluR(2/3) agonist LY379268 attenuate the expression of incubation of cocaine craving. Biol Psychiatry 61:591598. CrossRef Medline

Mahler SV, Berridge KC (2009) Which cue to "want?" Central amygdala opioid activation enhances and focuses incentive salience on a prepotent reward cue. J Neurosci 29:6500-6513. CrossRef Medline

McGaugh JL (2015) Consolidating memories. Annu Rev Psychol 66:1-24. CrossRef Medline

Namburi P, Beyeler A, Yorozu S, Calhoon GG, Halbert SA, Wichmann R, Holden SS, Mertens KL, Anahtar M, Felix-Ortiz AC, Wickersham IR, Gray JM, Tye KM (2015) A circuit mechanism for differentiating positive and negative associations. Nature 520:675-678. CrossRef Medline

Olds J, Milner P (1954) Positive reinforcement produced by electrical stimulation of septal area and other regions of rat brain. J Comp Physiol Psychol 47:419-427. CrossRef Medline

Paxinos G, Watson C (2007) The rat brain in stereotaxic coordinates, 6th ed. New York: Elsevier.

Peck CJ, Lau B, Salzman CD (2013) The primate amygdala combines information about space and value. Nat Neurosci 16:340-348. CrossRef Medline

Reppucci CJ, Petrovich GD (2016) Organization of connections between the amygdala, medial prefrontal cortex, and lateral hypothalamus: a single and double retrograde tracing study in rats. Brain Struct Funct 221:29372962. CrossRef Medline

Richardson NR, Roberts DC (1996) Progressive ratio schedules in drug selfadministration studies in rats: a method to evaluate reinforcing efficacy. J Neurosci Methods 66:1-11. CrossRef Medline

Robinson MJ, Warlow SM, Berridge KC (2014) Optogenetic excitation of central amygdala amplifies and narrows incentive motivation to pursue one reward above another. J Neurosci 34:16567-16580. CrossRef Medline

Saunders BT, Robinson TE (2011) Individual variation in the motivational properties of cocaine. Neuropsychopharmacology 36:1668-1676. CrossRef Medline

Seo DO, Funderburk SC, Bhatti DL, Motard LE, Newbold D, Girven KS, McCall JG, Krashes M, Sparta DR, Bruchas MR (2016) A GABAergic projection from the centromedial nuclei of the amygdala to ventromedial prefrontal cortex modulates reward behavior. J Neurosci 36:1083110842. CrossRef Medline

Shaham Y, Hope BT (2005) The role of neuroadaptations in relapse to drug seeking. Nat Neurosci 8:1437-1439. CrossRef Medline

Smith KS, Virkud A, Deisseroth K, Graybiel AM (2012) Reversible online control of habitual behavior by optogenetic perturbation of medial prefrontal cortex. Proc Natl Acad Sci U S A 109:18932-18937. CrossRef Medline

Stujenske JM, Spellman T, Gordon JA (2015) Modeling the spatiotemporal dynamics of light and heat propagation for in vivo optogenetics. Cell Rep 12:525-534. CrossRef Medline 
Swanson LW (2003) The amygdala and its place in the cerebral hemisphere. Ann N Y Acad Sci 985:174-184. Medline

Swanson LW, Petrovich GD (1998) What is the amygdala? Trends Neurosci 21:323-331. CrossRef Medline

Tang DW, Fellows LK, Small DM, Dagher A (2012) Food and drug cues activate similar brain regions: a meta-analysis of functional MRI studies. Physiol Behav 106:317-324. CrossRef Medline

Timberlake W, Grant DL (1975) Auto-shaping in rats to the presentation of another rat predicting food. Science 190:690-692. CrossRef

Timberlake W, Wahl G, King D (1982) Stimulus and response contingencies in the misbehavior of rats. J Exp Psychol Anim Behav Process 8:6285. CrossRef Medline

Tomie A, Brooks B, Zito B (1989) Contemporary learning theories: Pavlovian conditioning and the status of traditional learning theory. Hillsdale, NJ: Lawrence Erlbaum Associates.

Tye KM, Prakash R, Kim SY, Fenno LE, Grosenick L, Zarabi H, Thompson KR, Gradinaru V, Ramakrishnan C, Deisseroth K (2011) Amygdala circuitry mediating reversible and bidirectional control of anxiety. Nature 471:358-362. CrossRef Medline

Uslaner JM, Acerbo MJ, Jones SA, Robinson TE (2006) The attribution of incentive salience to a stimulus that signals an intravenous injection of cocaine. Behav Brain Res 169:320-324. CrossRef Medline

Volkow ND, Wang GJ, Tomasi D, Baler RD (2013) The addictive dimensionality of obesity. Biol Psychiatry 73:811-818. CrossRef Medline
Wassum KM, Izquierdo A (2015) The basolateral amygdala in reward learning and addiction. Neurosci Biobehav Rev 57:271-283. CrossRef Medline

Weiskrantz L (1956) Behavioral changes associated with ablation of the amygdaloid complex in monkeys. J Comp Physiol Psychol 49:381-391. CrossRef Medline

Witten IB, Steinberg EE, Lee SY, Davidson TJ, Zalocusky KA, Brodsky M, Yizhar O, Cho SL, Gong S, Ramakrishnan C, Stuber GD, Tye KM, Janak PH, Deisseroth K (2011) Recombinase-driver rat lines: tools, techniques, and optogenetic application to dopamine-mediated reinforcement. Neuron 72:721-733. CrossRef Medline

Wolff SB, Gründemann J, Tovote P, Krabbe S, Jacobson GA, Müller C, Herry C, Ehrlich I, Friedrich RW, Letzkus JJ, Lüthi A (2014) Amygdala interneuron subtypes control fear learning through disinhibition. Nature 509:453-458. CrossRef Medline

Yasoshima Y, Yoshizawa H, Shimura T, Miyamoto T (2015) The basolateral nucleus of the amygdala mediates caloric sugar preference over a noncaloric sweetener in mice. Neuroscience 291:203-215. CrossRef Medline

Yoshida K, McCormack S, España RA, Crocker A, Scammell TE (2006) Afferents to the orexin neurons of the rat brain. J Comp Neurol 494:845861. CrossRef Medline

Zahm DS (2006) The evolving theory of basal forebrain functional-anatomical “macrosystems'. Neurosci Biobehav Rev 30:148-172. CrossRef Medline 